\title{
Clinical practice parameters for hemodynamic support of pediatric and neonatal septic shock: 2007 update from the American College of Critical Care Medicine
}

\author{
A full list of authors and affiliations appears at the end of the article.
}

\begin{abstract}
Background-The Institute of Medicine calls for the use of clinical guidelines and practice parameters to promote "best practices" and to improve patient outcomes.

Objective-2007 update of the 2002 American College of Critical Care Medicine Clinical Guidelines for Hemodynamic Support of Neonates and Children with Septic Shock.

Participants-Society of Critical Care Medicine members with special interest in neonatal and pediatric septic shock were identified from general solicitation at the Society of Critical Care Medicine Educational and Scientific Symposia (2001-2006).
\end{abstract}

Methods-The Pubmed/MEDLINE literature database (1966-2006) was searched using the keywords and phrases: sepsis, septicemia, septic shock, endotoxemia, persistent pulmonary hypertension, nitric oxide, extracorporeal membrane oxygenation (ECMO), and American College of Critical Care Medicine guidelines. Best practice centers that reported best outcomes were identified and their practices examined as models of care. Using a modified Delphi method, 30 experts graded new literature. Over 30 additional experts then reviewed the updated recommendations. The document was subsequently modified until there was greater than $90 \%$ expert consensus.

Results-The 2002 guidelines were widely disseminated, translated into Spanish and Portuguese, and incorporated into Society of Critical Care Medicine and AHA sanctioned recommendations. Centers that implemented the 2002 guidelines reported best practice outcomes (hospital mortality $1 \%-3 \%$ in previously healthy, and $7 \%-10 \%$ in chronically ill children). Early use of 2002 guidelines was associated with improved outcome in the community hospital emergency department (number needed to treat $=3.3$ ) and tertiary pediatric intensive care setting (number needed to treat $=3.6$ ); every hour that went by without guideline adherence was associated with a 1.4-fold increased mortality risk. The updated 2007 guidelines continue to recognize an increased likelihood that children with septic shock, compared with adults, require 1)

Copyright $\odot 2009$ by the Society of Critical Care Medicine and Lippincott Williams \& Wilkins

For information regarding this article, carcilloja@ccm.upmc.edu.

The American College of Critical Care Medicine (ACCM), which honors individuals for their achievements and contributions to multidisciplinary critical care medicine, is the consultative body of the Society of Critical Care Medicine (SCCM) that possesses recognized expertise in the practice of critical care. The College has developed administrative guidelines and clinical practice parameters for the critical care practitioner. New guidelines and practice parameters are continually developed, and current ones are systematically reviewed and revised.

The remaining authors have not disclosed any potential conflicts of interest. 
proportionally larger quantities of fluid, 2) inotrope and vasodilator therapies, 3) hydrocortisone for absolute adrenal insufficiency, and 4) ECMO for refractory shock. The major new recommendation in the 2007 update is earlier use of inotrope support through peripheral access until central access is attained.

Conclusion-The 2007 update continues to emphasize early use of age-specific therapies to attain time-sensitive goals, specifically recommending 1) first hour fluid resuscitation and inotrope therapy directed to goals of threshold heart rates, normal blood pressure, and capillary refill $\underline{\Omega}$ secs, and 2) subsequent intensive care unit hemodynamic support directed to goals of central venous oxygen saturation $>70 \%$ and cardiac index $3.3-6.0 \mathrm{~L} / \mathrm{min} / \mathrm{m}^{2}$.

\section{Keywords}

guidelines; sepsis; severe sepsis

Neonatal and pediatric severe sepsis outcomes were already improving before 2002 with the advent of neonatal and pediatric intensive care (reduction in mortality from 97\% to 9\%) (14), and were markedly better than in adults (9\% compared with $28 \%$ mortality) (3). In 2002, the American College of Critical Care Medicine (ACCM) Clinical Practice Parameters for Hemodynamic Support of Pediatric and Neonatal Shock (5) were published, in part, to replicate the reported outcomes associated with implementation of "best clinical practices" (mortality rates of $0 \%-5 \%$ in previously healthy [6-8] and $10 \%$ in chronically ill children with septic shock [8]). There are two purposes served by this 2007 update of these 2002 clinical practice parameters. First, this 2007 document examines and grades new studies performed to test the utility and efficacy of the 2002 recommendations. Second, this 2007 document examines and grades relevant new treatment and outcome studies to determine to what degree, if any, the 2002 guidelines should be modified.

\section{METHODS}

More than 30 clinical investigators and clinicians affiliated with the Society of Critical Care Medicine who had special interest in hemodynamic support of pediatric patients with sepsis volunteered to be members of the "update" task force. Subcommittees were formed to review and grade the literature using the evidence-based scoring system of the ACCM. The literature was accrued, in part, by searching Pubmed/MEDLINE using the following keywords and phrases: sepsis, septicemia, septic shock, endotoxemia, persistent pulmonary hypertension (PPHN), nitric oxide (NO), and extracorporeal membrane oxygenation (ECMO). The search was narrowed to identify studies specifically relevant to children. Best practice outcomes were identified and described; clinical practice in these centers was used as a model.

The clinical parameters and guidelines were drafted and subsequently revised using a modification of the Delphi method. Briefly, the initial step included review of the literature and grading of the evidence by topic-based subcommittees during a 6-month period. Subcommittees were formed according to participant interest in each subtopic. The update recommendations from each subcommittee were incorporated into the preexisting 2002 document by the task force chairperson. All members commented on the unified update 
draft, and modifications were made in an iterative fashion until $<10 \%$ of the task force disagreed with any specific or general recommendation. This process occurred during a 1year period. Reviewers from the ACCM then requested further modifications that were considered for inclusion if supported by evidence and best practice. Grading of the literature and levels of recommendations were based on published ACCM criteria (Table 1).

\section{RESULTS}

\section{Successful Dissemination, Acceptance, Implementation, and Outcome of 2002 Guidelines}

The 2002 guidelines were initially distributed in the English language with official sanctioning by the Society for Critical Care Medicine with publication in Critical Care Medicine. The main pediatric algorithm was included in the Pediatric Advanced Life Support (PALS) manual published by the American Heart Association. In addition, the pediatric and newborn treatment algorithms were published in whole or part in multiple textbooks. The guidelines were subsequently published in Spanish and Portuguese allowing for dissemination in much of the American continents. There have been 57 peer-reviewed publications since 2002 that have cited these guidelines. Taken together these findings demonstrate academic acceptance and dissemination of the 2002 guidelines (Tables 2 and $3)$.

Many studies have tested the observations and recommendations of the 2002 guidelines. These studies reported evidence that the guidelines were useful and effective without any evidence of harm. For example, Wills et al (9) demonstrated near 100\% survival when fluid resuscitation was provided to children with dengue shock. Maitland et al (10) demonstrated a reduction in mortality from malaria shock from $18 \%$ to $4 \%$ when albumin was used for fluid resuscitation rather than crystalloid. Han et al reported an association between early use of practice consistent with the 2002 guidelines in the community hospital and improved outcomes in newborns and children (mortality rate $8 \%$ vs. $38 \%$; number needed to treat $[\mathrm{NNT}]=3.3$ ). Every hour that went by without restoration of normal blood pressure for age and capillary refill $<3$ secs was associated with a twofold increase in adjusted mortality odds ratio (11). Ninis et al (12) similarly reported an association between delay in inotrope resuscitation and a 22.6-fold increased adjusted mortality odds ratio in meningococcal septic shock. In a randomized controlled study, Oliveira et al (13) reported that use of the 2002 guidelines with continuous central venous oxygen saturation $\left(\mathrm{Scvo}_{2}\right)$ monitoring, and therapy directed to maintenance of $\mathrm{Scvo}_{2}>70 \%$, reduced mortality from $39 \%$ to $12 \%$ (NNT =3.6). In a before and after study, Lin et al (14) reported that implementation of the 2002 guidelines in a U.S. tertiary center achieved best practice outcome with a fluid refractory shock 28 -day mortality of $3 \%$ and hospital mortality of $6 \%$ (3\% in previously healthy children; $9 \%$ in chronically ill children). This outcome matched the best practice outcomes targeted by the 2002 guidelines (6-8). Similar to the experience of St. Mary's Hospital before 2002 (7), Sophia Children's Hospital in Rotterdam also recently reported a reduction in mortality rate from purpura and severe sepsis from $20 \%$ to $1 \%$ after implementation of 2002 guideline-based therapy in the referral center, transport system, and tertiary care settings (15). Both of these centers also used high flux continuous renal replacement therapy (CRRT) and fresh frozen plasma infusion directed to the goal of normal international 
normalized ratio (INR) (prothrombin time). In a U.S. child health outcomes database (Kids' Inpatient Database or KID) analysis, hospital mortality from severe sepsis was recently estimated to be $4.2 \%$ ( $2.3 \%$ in previously healthy children, and $7.8 \%$ in children with chronic illness) (16), a decrease compared with 9\% in 1999 (4). Taken together, these studies indirectly and directly support the utility and efficacy of implementation of the timesensitive, goal-directed recommendations of the 2002 guidelines in the emergency/ delivery room and pediatric intensive care unit/neonatal intensive care unit settings.

\section{New Major Recommendations in the 2007 Update}

Because of the success of the 2002 guidelines, the 2007 update compilation and discussion of the new literature were directed to the question of what changes, if any, should be implemented in the update. The members of the committee were asked whether there are clinical practices which the best outcome practices are using in 2007 that were not recommended in the 2002 guidelines and should be recommended in the 2007 guidelines? The changes recommended were few. Most importantly, there was no change in emphasis between the 2002 guidelines and the 2007 update. The continued emphasis is directed to: 1) first hour fluid resuscitation and inotrope drug therapy directed to goals of threshold heart rates (HR), normal blood pressure, and capillary refill $\mathcal{Q}$ secs, and 2) subsequent intensive care unit hemodynamic support directed to goals of $\mathrm{Scvo}_{2}>70 \%$ and cardiac index 3.3-6.0 $\mathrm{L} / \mathrm{min} / \mathrm{m}^{2}$. New recommendations in the 2007 update include the following: 1) The 2002 guidelines recommended not giving cardiovascular agents until central vascular access was attained. This was because there was and still is concern that administration of peripheral vasoactive agents (especially vasopressors) could result in peripheral vascular/tissue injury. However, after implementation of the 2002 guidelines, the literature showed that, depending on availability of skilled personnel, it could take two or more hours to establish central access. Because mortality went up with delay in time to inotrope drug use, the 2007 update now recommends use of peripheral inotropes (not vasopressors) until central access is attained. The committee continues to recommend close monitoring of the peripheral access site to prevent peripheral vascular/tissue injury; 2) The 2002 guidelines made no recommendations on what sedative/analgesic agent(s) to use to facilitate placement of central lines and/or intubation. Multiple editorials and cohort studies have since reported that the use of etomidate was associated with increased severity of illness adjusted mortality in adults and children with septic shock. The 2007 update now states that etomidate is not recommended for children with septic shock unless it is used in a randomized controlled trial format. For now, the majority of the committee uses atropine and ketamine for invasive procedures in children with septic shock. Little experience is available with ketamine use in newborn septic shock and the committee makes no recommendation in this population; 3 ) Since 2002, cardiac output (CO) can be measured not only with a pulmonary artery catheter, but also with Doppler echocardiography, or a pulse index contour cardiac output catheter catheter, or a femoral artery thermodilution catheter. Titration of therapy to CO 3.3-6.0 $\mathrm{L} / \mathrm{min} / \mathrm{m}^{2}$ remains the goal in patients with persistent catecholamine resistant shock in 2007 guidelines. Doppler echocardiography can also be used to direct therapies to a goal of superior vena cava (SVC) flow $>40 \mathrm{~mL} / \mathrm{min} / \mathrm{kg}$ in very low birth weight (VLBW) infants; 4) There are several new potential rescue therapies reported since the 2002 guidelines. In children, enoximone and levosimendan have been highlighted in case series and case 
reports. Unlike vasopressin, which had been suggested by some as a vasoplegia rescue therapy, these agents are suggested by some as recalcitrant cardiogenic shock rescue agents. In newborns, inhaled prostacyclin and intravenous (IV) adenosine were reportedly successful in refractory PPHN. The 2007 update recommends further evaluation of these new agents in appropriate patient settings; and 5) The 2002 guidelines made no recommendation on fluid removal. Although fluid resuscitation remains the hallmark and first step of septic shock resuscitation, two cohort studies showed the importance of fluid removal in fluid overloaded septic shock/ multiple organ failure patients. The 2007 update recommends that fluid removal using diuretics, peritoneal dialysis, or CRRT is indicated in patients who have been adequately fluid resuscitated but cannot maintain subsequent evenfluid balance through native urine output. This can be done when such patients develop new onset hepatomegaly, rales, or $10 \%$ body weight fluid overload.

\section{Literature and Best Practice Review}

\section{Developmental Differences in the Hemodynamic Response to Sepsis in} Newborns, Children, and Adults-The predominant cause of mortality in adult septic shock is vasomotor paralysis (17). Adults have myocardial dysfunction manifested as a decreased ejection fraction; however, $\mathrm{CO}$ is usually maintained or increased by two mechanisms: tachycardia and reduced systemic vascular resistance (SVR). Adults who do not develop this process to maintain CO have a poor prognosis $(18,19)$. Pediatric septic shock is associated with severe hypovolemia, and children frequently respond well to aggressive volume resuscitation; however, the hemodynamic response of fluid resuscitated vasoactive-dependent children seems diverse compared with adults. Contrary to the adult experience, low CO, not low SVR, is associated with mortality in pediatric septic shock (2029). Attainment of the therapeutic goal of CI $3.3-6.0 \mathrm{~L} / \mathrm{min} / \mathrm{m}^{2}$ may result in improved survival $(21,29)$. Also contrary to adults, a reduction in oxygen delivery rather than a defect in oxygen extraction, can be the major determinant of oxygen consumption in children (22). Attainment of the therapeutic goal of oxygen consumption $\left(\mathrm{Vo}_{2}\right)>200 \mathrm{~mL} / \mathrm{min} / \mathrm{m}^{2}$ may also be associated with improved outcome (21).

It was not until 1998 that investigators reported patient outcome when aggressive volume resuscitation $(60 \mathrm{~mL} / \mathrm{kg}$ fluid in the first hour) and goal-directed therapies (goal, CI 3.3-6.0 $\mathrm{L} / \mathrm{min} / \mathrm{m}^{2}$ and normal pulmonary capillary wedge pressure) (21) were applied to children with septic shock (29). Ceneviva et al (29) reported 50 children with fluid-refractory ( $\ 60$ $\mathrm{mL} / \mathrm{kg}$ in the first hour), dopamine-resistant shock. The majority (58\%) showed a low CO/ high SVR state, and 22\% had low CO and low vascular resistance. Hemodynamic states frequently progressed and changed during the first $48 \mathrm{hrs}$. Persistent shock occurred in $33 \%$ of the patients. There was a significant decrease in cardiac function over time, requiring addition of inotropes and vasodilators. Although decreasing cardiac function accounted for the majority of patients with persistent shock, some showed a complete change from a low output state to a high output/low SVR state (30-33). Inotropes, vasopressors, and vasodilators were directed to maintain normal $\mathrm{CI}$ and SVR in the patients. Mortality from fluid-refractory, dopamine-resistant septic shock in this study (18\%) was markedly reduced compared with mortality in the 1985 study (58\%) (29), in which aggressive fluid resuscitation was not used. Since 2002, investigators have used Doppler ultrasound to 
measure $\mathrm{CO}$ (34), and similarly reported that previously healthy children with meningococcemia often had a low $\mathrm{CO}$ with a high mortality rate, whereas $\mathrm{CO}$ was high and mortality rate was low in septic shock related to catheter-associated blood stream infections.

Neonatal septic shock can be complicated by the physiologic transition from fetal to neonatal circulation. In utero, $85 \%$ of fetal circulation bypasses the lungs through the ductus arteriosus and foramen ovale. This flow pattern is maintained by suprasystemic pulmonary vascular resistance in the prenatal period. At birth, inhalation of oxygen triggers a cascade of biochemical events that ultimately result in reduction in pulmonary vascular resistance and artery pressure and transition from fetal to neonatal circulation with blood flow now being directed through the pulmonary circulation. Closure of the ductus arteriosus and foramen ovale complete this transition. Pulmonary vascular resistance and artery pressures can remain elevated and the ductus arteriosus can remain open for the first 6 wks of life, whereas the foramen ovale may remain probe patent for years. Sepsis-induced acidosis and hypoxia can increase pulmonary vascular resistance and thus arterial pressure and maintain patency of the ductus arteriosus, resulting in PPHN of the newborn and persistent fetal circulation. Neonatal septic shock with PPHN can be associated with increased right ventricle work. Despite in utero conditioning, the thickened right ventricle may fail in the presence of systemic pulmonary artery pressures. Decompensated right ventricular failure can be clinically manifested by tricuspid regurgitation and hepatomegaly. Newborn animal models of group B streptococcal and endotoxin shock have also documented reduced $\mathrm{CO}$, and increased pulmonary, mesenteric, and SVR (35-39). Therapies directed at reversal of right ventricle failure, through reduction of pulmonary artery pressures, are commonly needed in neonates with fluid-refractory shock and PPHN.

The hemodynamic response in premature, VLBW infants with septic shock ( $<32$ wks gestation, $<1000 \mathrm{~g}$ ) is least understood. Most hemodynamic information is derived only from echocardiographic evaluation and there are few septic shock studies in this population. Neonatology investigators often fold septic shock patients into "respiratory distress syndrome" and "shock" studies rather than conduct septic shock studies alone. Hence, the available clinical evidence on the hemodynamic response in premature infants for the most part is in babies with respiratory distress syndrome or shock of undescribed etiology. In the first 24 hrs after birth during the "transitional phase," the neonatal heart must rapidly adjust to a high vascular resistance state compared with the low resistance placenta. $\mathrm{CO}$ and blood pressure may decrease when vascular resistance is increased (40). However, the literature indicates that premature infants with shock can respond to volume and inotropic therapies with improved stroke volume (SV), contractility, and blood pressure (41-54).

Several other developmental considerations influence shock therapy in the premature infant. Relative initial deficiencies in the thyroid and parathyroid hormone axes have been reported and can result in the need for thyroid hormone and/or calcium replacement. $(55,56)$

Hydrocortisone has been examined in this population as well. Since 2002, randomized controlled trials showed that prophylactic use of hydrocortisone on day 1 of life reduced the incidence of hypotension in this population, (57) and a 7-day course of hydrocortisone reduced the need for inotropes in VLBW infants with septic shock (58-60). Immature mechanisms of thermogenesis require attention to external warming. Reduced glycogen 
stores and muscle mass for gluconeogenesis require attention to maintenance of serum glucose concentration. Standard practices in resuscitation of preterm infants in septic shock use a more graded approach to volume resuscitation and vasopressor therapy compared with resuscitation of term neonates and children. This more cautious approach is a response to anecdotal reports that preterm infants at risk for intraventricular hemorrhage $(<30 \mathrm{wks}$ gestation) can develop hemorrhage after rapid shifts in blood pressure; however, some now question whether long-term neurologic outcomes are related to periventricular leukomalacia (a result of prolonged under perfusion) more than to intraventricular hemorrhage. Another complicating factor in VLBW infants is the persistence of the patent ductus arteriosus. This can occur because immature muscle is less able to constrict. The majority of infants with this condition are treated medically with indomethacin, or in some circumstances with surgical ligation. Rapid administration of fluid may further increase left to right shunting through the ductus with ensuant pulmonary edema.

One single-center randomized control trial reported improved outcome with use of daily 6hr pentoxyfilline infusions in very premature infants with sepsis $(61,62)$. This compound is both a vasodilator and an anti-inflammatory agent. A Cochrane analysis agrees that this promising therapy deserves evaluation in a multicentered trial setting (63).

\section{What Clinical Signs and Hemodynamic Variables Can be Used to Direct Treatment of Newborn and Pediatric Shock?}

Shock can be defined by clinical variables, hemodynamic variables, oxygen utilization variables, and/or cellular variables; however, after review of the literature, the committee continues to choose to define septic shock by clinical, hemodynamic, and oxygen utilization variables only. This decision may change at the next update. For example, studies demonstrate that blood troponin concentrations correlate well with poor cardiac function and response to inotropic support in children with septic shock (64-66). Lactate is recommended in adult septic shock laboratory testing bundles for both diagnosis and subsequent monitoring of therapeutic responses. However, most adult literature continues to define shock by clinical hypotension, and recommends using lactate concentration to identify shock in normotensive adults. For now the overall committee recommends early recognition of pediatric septic shock using clinical examination, not biochemical tests. Two members dissent from this recommendation and suggest use of lactate as well.

Ideally, shock should be clinically diagnosed before hypotension occurs by clinical signs, which include hypothermia or hyperthermia, altered mental status, and peripheral vasodilation (warm shock) or vasoconstriction with capillary refill >2 secs (cold shock). Threshold HR associated with increased mortality in critically ill (not necessarily septic) infants are a HR $<90$ beats per minute (bpm) or $>160 \mathrm{bpm}$, and in children are a HR $<70$ bpm or $>150 \mathrm{bpm}$ (67). Emergency department therapies should be directed toward restoring normal mental status, threshold HRs, peripheral perfusion (capillary refill $<3$ secs), palpable distal pulses, and normal blood pressure for age (Table 3) (11). Orr et al reported that specific hemodynamic abnormalities in the emergency department were associated with progressive mortality (in parenthesis); eucardia $(1 \%)<$ tachycardia/ bradycardia $(3 \%)<$ hypotension with capillary refill $<3 \operatorname{secs}(5 \%)<$ normo-tension with capillary refill greater 
than 3 secs $(7 \%)<$ hypotension with capillary refill greater than 3 secs (33\%). Reversal of these hemodynamic abnormalities using ACCM/PALS recommended therapy was associated with a $40 \%$ reduction in mortality odds ratio regardless of the stage of hemodynamic abnormality at the time of presentation (68). One member of the committee wishes to emphasize that these signs are important only if the patients are considered ill.

In both neonates and children, shock should be further evaluated and resuscitation treatment guided by hemodynamic variables including perfusion pressure (mean arterial pressure [MAP] minus central venous pressure) and $\mathrm{CO}$. As previously noted, blood flow $(Q)$ varies directly with perfusion pressure $(\mathrm{d} P)$ and inversely with resistance $(R)$. This is mathematically represented by $Q=\mathrm{d} P / R$. For the systemic circulation this is represented by $\mathrm{CO}=(\mathrm{MAP}-$ central venous pressure $) / \mathrm{SVR}$. This relationship is important for organ perfusion. In the kidney, for example, renal blood flow $=$ (mean renal arterial pressure mean renal venous pressure)/renal vascular resistance. The kidney and brain have vasomotor autoregulation, which maintains blood flow in low blood pressure (MAP or renal arterial pressure) states. At some critical point, perfusion pressure is reduced below the ability of the organ to maintain blood flow.

One goal of shock treatment is to maintain perfusion pressure above the critical point below which blood flow cannot be effectively maintained in individual organs. The kidney receives the second highest blood flow relative to its mass of any organ in the body, and measurement of urine output (with the exception of patients with hyperosmolar states such as hyperglycemia which leads to osmotic diuresis) and creatinine clearance can be used as an indicator of adequate blood flow and perfusion pressure. Maintenance of MAP with norepinephrine has been shown to improve urine output and creatinine clearance in hyperdynamic sepsis (69). Producing a supranormal MAP above this point is likely not of benefit (70).

Reduction in perfusion pressure below the critical point necessary for adequate splanchnic organ perfusion can also occur in disease states with increased intraabdominal pressure (IAP) such as bowel wall edema, ascites, or abdominal compartment syndrome. If this increased IAP is not compensated for by an increase in contractility that improves MAP despite the increase in vascular resistance, then splanchnic perfusion pressure is decreased. Therapeutic reduction of IAP (measured by intrabladder pressure) using diuretics and/or peritoneal drainage for IAP > $12 \mathrm{~mm} \mathrm{Hg}$, and surgical decompression for $>30 \mathrm{~mm} \mathrm{Hg}$, results in restoration of perfusion pressure and has been shown to improve renal function in children with burn shock (71).

Normative blood pressure values in the VLBW newborn have been reassessed. A MAP $<30$ $\mathrm{mm} \mathrm{Hg}$ is associated with poor neurologic outcome and survival, and is considered the absolute minimum tolerable blood pressure in the extremely premature infant (42). Because blood pressure does not necessarily reflect $\mathrm{CO}$, it is recommended that normal $\mathrm{CO}$ and/or SVC flow, measured by Doppler echocardiography, be a primary goal as well (72-82).

Although perfusion pressure is used as a surrogate marker of adequate flow, the previous equation shows that organ blood flow $(Q)$ correlates directly with perfusion pressure and 
inversely with vascular resistance. If the ventricle is healthy, an elevation of SVR results in hypertension with maintenance of $\mathrm{CO}$. Conversely, if ventricular function is reduced, the presence of normal blood pressure with high vascular resistance means that $\mathrm{CO}$ is reduced. If the elevation in vascular resistance is marked, the reduction in blood flow results in shock.

A CI between 3.3 and $6.0 \mathrm{~L} / \mathrm{min} / \mathrm{m}^{2}$ is associated with best outcomes in septic shock patients (21) compared with patients without septic shock for whom a CI above 2.0 $\mathrm{L} / \mathrm{min} / \mathrm{m}^{2}$ is sufficient (83). Attainment of this $\mathrm{CO}$ goal is often dependent on attaining threshold HRs. However, if the HR is too high, then there is not enough time to fill the coronary arteries during diastole, and contractility and $\mathrm{CO}$ will decrease. Coronary perfusion may be further reduced when an unfavorable transmural coronary artery filling pressure is caused by low diastolic blood pressure (DBP) and/or high end-diastolic ventricular pressure. In this scenario, efforts should be made to improve coronary perfusion pressure and reverse the tachycardia by giving volume if the SV is low, or an inotrope if contractility is low. Because $\mathrm{CO}=\mathrm{HR} \times \mathrm{SV}$, therapies directed to increasing SV will often reflexively reduce HR and improve CO. This will be evident in improvement of the shock index (HR/systolic blood pressure), as well as CO. Children have limited HR reserve compared with adults because they are already starting with high basal HRs. For example, if SV is reduced due to endotoxin-induced cardiac dysfunction, an adult can compensate for the fall in SV by increasing HR two-fold from 70 to $140 \mathrm{bpm}$, but a baby cannot increase her HR from 140 $\mathrm{bpm}$ to $280 \mathrm{bpm}$. Although tachycardia is an important method for maintaining $\mathrm{CO}$ in infants and children, the younger the patient, the more likely this response will be inadequate and the $\mathrm{CO}$ will fall. In this setting, the response to falling SV and contractility is to vasoconstrict to maintain blood pressure. Increased vascular resistance is clinically identified by absent or weak distal pulses, cool extremities, prolonged capillary refill, and narrow pulse pressure with relatively increased DBP. The effective approach for these children is vasodilator therapy with additional volume loading as vascular capacity is expanded. Vasodilator therapy reduces afterload and increases vascular capacitance. This shifts the venous compliance curve so that more volume can exist in the right and left ventricles at a lower pressure. In this setting, giving volume to restore filling pressure results in a net increase in end-diastolic volume (i.e., preload) and a higher $\mathrm{CO}$ at the same or lower filling pressures. Effective use of this approach results in a decreased HR and improved perfusion.

At the other end of the spectrum, a threshold minimum HR is also needed because if the HR is too low then $\mathrm{CO}$ will be too low $(\mathrm{CO}=\mathrm{HR} \times \mathrm{SV})$. This can be attained by using an inotrope that is also a chronotrope. In addition to threshold HRs, attention must also be paid to DBP. If the DBP-central venous pressure is too low then addition of an inotrope/ vasopressor agent such as norepinephrine may be required to improve diastolic coronary blood flow. Conversely, if wall stress is too high due to an increased end-diastolic ventricular pressure and diastolic volume secondary to fluid overload, then a diuretic may be required to improve SV by moving leftward on the overfilled Starling function curve. The effectiveness of these maneuvers will similarly be evidenced by improvement in the HR/ systolic blood pressure shock index, CO, and SVR along with improved distal pulses, skin temperature, and capillary refill. 
Shock should also be assessed and treated according to oxygen utilization measures. Measurement of $\mathrm{CO}$ and $\mathrm{O}_{2}$ consumption were proposed as being of benefit in patients with persistent shock because a CI between 3.3 and $6.0 \mathrm{~L} / \mathrm{min} / \mathrm{m}^{2}$ and $\mathrm{O}_{2}$ consumption $>200$ $\mathrm{mL} / \mathrm{min} / \mathrm{m}^{2}$ are associated with improved survival (21). Low CO is associated with increased mortality in pediatric septic shock (20-29). In one study, children with fluidrefractory, dopamine-resistant shock were treated with goal-directed therapy (CI $>3.3$ and $<6 \mathrm{~L} / \mathrm{min} / \mathrm{m}^{2}$ ) and found to have improved outcomes compared with historical reports (29). Because low $\mathrm{CO}$ is associated with increased $\mathrm{O}_{2}$ extraction, (22) $\mathrm{Scvo}_{2}$ saturation can be used as an indirect indicator of whether $\mathrm{CO}$ is adequate to meet tissue metabolic demand. If tissue oxygen delivery is adequate, then assuming a normal arterial oxygen saturation of $100 \%$, mixed venous saturation is $>70 \%$. Assuming a hemoglobin concentration of $10 \mathrm{~g} / \mathrm{dL}$ and $100 \%$ arterial $\mathrm{O}_{2}$ saturation then a $\mathrm{CI}>3.3 \mathrm{~L} / \mathrm{min} / \mathrm{m}^{2}$ with a normal oxygen consumption of $150 \mathrm{~mL} / \mathrm{min} / \mathrm{m}^{2}\left(\mathrm{O}_{2}\right.$ consumption $=\mathrm{CI} \times$ [arterial $\mathrm{O}_{2}$ content - venous $\mathrm{O}_{2}$ content]) results in a mixed venous saturation of $>70 \%$ because $150 \mathrm{~mL} / \mathrm{min} / \mathrm{m}^{2}=3.3$ $\mathrm{L} / \mathrm{min} / \mathrm{m}^{2} \times\left[1.39 \times 10 \mathrm{~g} / \mathrm{dL}+\mathrm{PaO}_{2} \times 0.003\right] \times 10 \times[1-0.7]$. In an emergency department study in adults with septic shock, maintenance of $\mathrm{SVC} \mathrm{O}_{2}$ saturation $>70 \%$ by use of blood transfusion to a hemoglobin of $10 \mathrm{~g} / \mathrm{dL}$ and inotropic support to increase $\mathrm{CO}$, resulted in a $40 \%$ reduction in mortality compared with a group in whom MAP and central venous pressure were maintained at usual target values without attention to $\mathrm{SVC} \mathrm{O}_{2}$ saturation (84). Since 2002, Oliveira et al (13) reproduced this finding in children with septic shock reducing mortality from $39 \%$ to $12 \%$ when directing therapy to the goal of $\mathrm{Scvo}_{2}$ saturation $>70 \%$ (NNT 3.6).

In VLBW infants, SVC blood flow measurement was reportedly useful in assessing the effectiveness of shock therapies. The SVC flow approximates blood flow from the brain. A value $>40 \mathrm{~mL} / \mathrm{kg} / \mathrm{min}$ is associated with improved neurologic outcomes and survival (7882). $\mathrm{Scvo}_{2}$ saturation can be used in low birth weight infants but may be misleading in the presence of left to right shunting through the patent ductus arteriosus.

Intravascular Access-Vascular access for fluid resuscitation and inotrope/ vasopressor infusion is more difficult to attain in newborns and children compared with adults. To facilitate a rapid approach to vascular access in critically ill infants and children, the American Heart Association and the American Academy of Pediatrics developed neonatal resuscitation program and PALS guidelines for emergency establishment of intravascular support $(85,86)$. Essential age-specific differences include use of umbilical artery and umbilical venous access in newborns, and rapid use of intraosseous access in children. Ultrasound guidance may have a role in the placement of central lines in children.

Fluid Therapy-Several fluid resuscitation trials have been performed since 2002. For example, several randomized trials showed that when children with mostly stage III (narrow pulse pressure/ tachycardia) and some stage IV (hypotension) World Health Organization classification dengue shock received fluid resuscitation in the emergency department, there was near $100 \%$ survival regardless of the fluid composition used $(6,9,87,88)$. In a randomized controlled trial, Maitland et al (10) demonstrated a reduction in malaria septic shock mortality from $18 \%$ to $4 \%$ when albumin was used compared with crystalloid. The 
large randomized adult SAFE trial that compared crystalloid vs. albumin fluid resuscitation reported a trend toward improved outcome $(p<0.1)$ in septic shock patients who received albumin (89). Preference for the exclusive use of colloid resuscitation was made based on a clinical practice position article from a group who reported outstanding clinical results in resuscitation of meningococcal septic shock (5\% mortality) both using $4 \%$ albumin exclusively ( $20 \mathrm{~mL} / \mathrm{kg}$ boluses over 5-10 mins) and intubating and ventilating all children who required greater than $40 \mathrm{~mL} / \mathrm{kg}$ (7). In an Indian trial of fluid resuscitation of pediatric septic shock, there was no difference in outcome with gelatin compared with crystalloid (90). In the initial clinical case series that popularized the use of aggressive volume resuscitation for reversal of pediatric septic shock, a combination of crystalloid and colloid therapies was used (91). Several new investigations examined both the feasibility of the 2002 guideline recommendation of rapid fluid resuscitation as well as the need for fluid removal in patients with subsequent oliguria after fluid resuscitation. The 2002 guideline recommended rapid $20 \mathrm{~mL} / \mathrm{kg}$ fluid boluses over 5 mins followed by assessment for improved perfusion or fluid overload as evidenced by new onset rales, increased work of breathing, and hypoxemia from pulmonary edema, hepatomegaly, or a diminishing MAPcentral venous pressure. Emergency medicine investigators reported that $20 \mathrm{~mL} / \mathrm{kg}$ of crystalloid or colloid can be pushed over 5 mins, or administered via a pressure bag over 5 mins through a peripheral and/or central IV line (92). Ranjit et al (93) reported improved outcome from dengue and bacterial septic shock when they implemented a protocol of aggressive fluid resuscitation followed by fluid removal using diuretics and/or peritoneal dialysis if oliguria ensued. In this regard, Foland et al (94) similarly reported that patients with multiple organ failure who received CRRT when they were $<10 \%$ fluid overloaded had better outcomes than those who were $>10 \%$ fluid overloaded. Similarly, two best outcome practices reported routine use of CRRT to prevent fluid overload while correcting prolonged INR with plasma infusion in patients with purpura and septic shock $(7,15)$.

The use of blood as a volume expander was examined in two small pediatric observational studies, but no recommendations were given by the investigators $(95,96)$. In the previously mentioned study by Oliveira et al (13) reporting improved outcome with use of the 2002 ACCM guidelines and continuous $\mathrm{Scvo}_{2}$ saturation monitoring, the treatment group received more blood transfusions directed to improvement of $\mathrm{Scvo}_{2}$ saturation to $>70 \%$ (40\% vs. 7\%). This finding agrees with the results of Rivers (84) who transfused patients with a SVC oxygen saturation $<70 \%$ to assure a hemoglobin of $10 \mathrm{~g} / \mathrm{dL}$ as part of goal-directed therapy based on central venous oxygen saturation. Although the members of the task force use conservative goals for blood transfusion in routine critical illness, the observations that for patients with septic shock, transfusion to a goal hemoglobin $>10 \mathrm{~g} / \mathrm{dL}$ to achieve $\mathrm{ScvO}_{2}$ $>70 \%$ is associated with increased survival suggests that this higher hemoglobin goal is warranted in this population.

Fluid infusion is best initiated with boluses of $20 \mathrm{~mL} / \mathrm{kg}$, titrated to assuring an adequate blood pressure and clinical monitors of $\mathrm{CO}$ including HR, quality of peripheral pulses, capillary refill, level of consciousness, peripheral skin temperature, and urine output. Initial volume resuscitation commonly requires $40-60 \mathrm{~mL} / \mathrm{kg}$ but can be as much as $200 \mathrm{~mL} / \mathrm{kg}$ $(28,91,97-104)$. Patients who do not respond rapidly to initial fluid boluses, or those with 
insufficient physiologic reserve, should be considered for invasive hemodynamic monitoring. Monitoring filling pressures can be helpful to optimize preload and thus CO. Observation of little change in the central venous pressure in response to a fluid bolus suggests that the venous capacitance system is not overfilled and that more fluid is indicated. Observation that an increasing central venous pressure is met with reduced MAP-central venous pressure suggests that too much fluid has been given. Large volumes of fluid for acute stabilization in children have not been shown to increase the incidence of the acute respiratory distress syndrome $(91,103)$ or cerebral edema $(91,104)$. Increased fluid requirements may be evident for several days secondary to loss of fluid from the intravascular compartment when there is profound capillary leak (28). Routine fluid choices include crystalloids (normal saline or lactated Ringers) and colloids (dextran, gelatin, or 5\% albumin) $(6,105-114)$. Fresh frozen plasma may be infused to correct abnormal prothrombin time and partial thromboplastin time values, but should not be pushed because it may produce acute hypotensive effects likely caused by vasoactive kinins and high citrate concentration. Because oxygen delivery depends on hemoglobin concentration, hemoglobin should be maintained at a minimum of $10 \mathrm{~g} / \mathrm{dL}(13,84)$. Diuretics/peritoneal dialysis/CRRT are indicated for patients who develop signs and symptoms of fluid overload.

Mechanical Ventilation-There are several reasons to initiate intubation and ventilation in relation to the hemodynamic support of patients with septic shock. In practice, the first indication is usually the need to establish invasive hemodynamic monitoring. In uncooperative, coagulopathic infants, this is most safely accomplished in the sedated, immobilized patient. This step should be considered in any patient who is not rapidly stabilized with fluid resuscitation and peripherally administered inotropes.

Ventilation also provides mechanical support for the circulation. Up to $40 \%$ of CO may be required to support the work of breathing, and this can be unloaded by ventilation, diverting flow to vital organs. Increased intrathoracic pressure also reduces left ventricular afterload that may be beneficial in patients with low CI and high SVR. Ventilation may also provide benefits in patients with elevated pulmonary vascular resistance. Mild hyperventilation may also be used to compensate for metabolic acidosis by altering the respiratory component of acid-base balance. Caution must be exercised as excessive ventilation may impair CO, particularly in the presence of hypovolemia. Additional volume loading is often necessary at this point.

Sedation and ventilation also facilitate temperature control and reduce oxygen consumption. Importantly but less commonly, ventilation is required because of clinical and laboratory evidence of respiratory failure, impaired mental state, or moribund condition.

Sedation for Invasive Procedures or Intubation-Airway and breathing can initially be managed according to PALS guidelines using head positioning, and a high flow oxygen delivery system. A report published since 2002 supports early management of dengue shock using high flow nasal cannula $\mathrm{O}_{2}$ /continuous positive airway pressure (115). When intubation or invasive procedures are required, patients are at risk of worsening hypotension from the direct myocardial depressant and vasodilator effects of induction agents as well as indirect effects due to blunting of endogenous catecholamine release. Propofol, thiopental, 
benzodiaz-epines, and inhalational agents all carry these risks. Yamamoto (116) and others $(7,15)$ suggest using ketamine with atropine premedication for sedation and intubation in septic shock. Ketamine is a central NMDA receptor blocker, which blocks nuclear factorkappa B transcription and reduces systemic interleukin-6 production while maintaining an intact adrenal axis, which in turn maintains cardiovascular stability (117-125). Ketamine can also be used as a sedation/ analgesia infusion to maintain cardiovascular stability during mechanical ventilation (126). Etomidate is popular as an induction agent because it maintains cardiovascular stability through blockade of the vascular $\mathrm{K}+$ channel; however, even one dose used for intubation is independently associated with increased mortality in both children and adults with septic shock, possibly secondary to inhibition of adrenal corticosteroid biosynthesis. Therefore, it is not recommended for this purpose (127-131). Only one member of the task force continues to support use of etomidate in pediatric septic shock with the caveat that stress dose hydrocortisone be administered. Little has been published on the use of ketamine or etomidate in newborns with shock so we cannot make recommendations for or against the use of these drugs in newborns. When intubation and ventilation are required the use of neuromuscular blocking agents should be considered.

Intravascular Catheters and Monitoring-Minimal invasive monitoring is necessary in children with fluid-responsive shock; however, central venous access and arterial pressure monitoring are recommended in children with fluid-refractory shock. Maintenance of perfusion pressure (MAP-central venous pressure), or (MAP-IAP) if the abdomen is tense secondary to bowel edema or ascitic fluid, is considered necessary for organ perfusion (38). Echocardiography is considered an appropriate noninvasive tool to rule out the presence of pericardial effusion, evaluate contractility, and depending on the skills of the echocardiographer, check ventricular filling. Doppler echocardiography can be used to measure $\mathrm{CO}$ and SVC flow. $\mathrm{CO}>3.3 \mathrm{~L} / \mathrm{min} / \mathrm{m}^{2}<6.0 \mathrm{~L} / \mathrm{min} / \mathrm{m}^{2}$ and $\mathrm{SVC}$ flow $>40$ $\mathrm{mL} / \mathrm{kg} / \mathrm{min}$ in newborns are associated with improved survival and neurologic function. Goal-directed therapy to achieve an $\mathrm{Scvo}_{2}$ saturation $>70 \%$ is associated with improved outcome (13). To gain accurate measures of $\mathrm{Scvo}_{2}$, the tip of the catheter must be at or close to the SVC-right atrial or inferior vena cava-right atrial junction (132). A pulmonary artery catheter, pulse index contour cardiac output catheter, or femoral artery thermodilution catheter can be used to measure $\mathrm{CO}$ (133) in those who remain in shock despite therapies directed to clinical signs of perfusion, MAP-central venous pressure, $\mathrm{Scvo}_{2}$, and echocardiographic analyses (134-144). The pulmonary artery catheter measures the pulmonary artery occlusion pressure to help identify selective left ventricular dysfunction, and can be used to determine the relative contribution of right and left ventricle work. The pulse index contour cardiac output catheter estimates global end-diastolic volume in the heart (both chambers) and extravascular lung water and can be used to assess whether preload is adequate. None of these techniques is possible in neonates and smaller infants. Other noninvasive monitors undergoing evaluation in newborns and children include percutaneous venous oxygen saturation, aortic ultrasound, perfusion index (pulse-oximetry), near infrared spectroscopy, sublingual $\mathrm{Pco}_{2}$, and sublingual microvascular orthogonal polarization spectroscopy scanning. All show promise; however, none have been tested in goal-directed therapy trials (145-152). 


\section{Cardiovascular Drug Therapy}

When considering the use of cardiovascular agents in the management of infants and children with septic shock, several important points need emphasis. The first is that septic shock represents a dynamic process so that the agents selected and their infusion dose may have to be changed over time based on the need to maintain adequate organ perfusion. It is also important to recognize that the vasoactive agents are characterized by varying effects on SVR and pulmonary vascular resistance (i.e., vasodilators or vasopressors), contractility (i.e., inotropy) and HR (chronotropy). These pharmacologic effects are determined by the pharmacokinetics of the agent and the pharmacodynamics of the patient's response to the agent. In critically ill septic children, perfusion and function of the liver and kidney are often altered, leading to changes in drug pharmacokinetics with higher concentrations observed than anticipated. Thus, the infusion doses quoted in many textbooks are approximations of starting rates and should be adjusted based on the patient's response. The latter is also determined by the pharmacodynamic response to the agent, which is commonly altered in septic patients. For example, patients with sepsis have a well-recognized reduced response to alpha-adrenergic agonists that is mediated by excess NO production as well as alterations in the alpha-adrenergic receptor system. Similarly, cardiac beta-adrenergic responsiveness may be reduced by the effect of NO and other inflammatory cytokines.

\section{Inotropes}

Dopamine (5-9 $\mu \mathrm{g} / \mathrm{kg} / \mathrm{min})$, dobutamine, or epinephrine $(0.05-0.3 \mu \mathrm{g} / \mathrm{kg} / \mathrm{min})$ can be used as first-line inotropic support. Dobutamine may be used when there is a low CO state with adequate or increased SVR $(29,84,153-165)$. Dobutamine or mid-dosage dopamine can be used as the first line of inotropic support if supported by clinical and objective data (e.g., assessment of contractility by echocardiogram) when one of the initial goals is to increase cardiac contractility in patients with normal blood pressure. However, children $<12$ months may be less responsive (161). Recent adult data raises the concern of increased mortality with the use of dopamine (166). There is not a clear explanation for these observations. Possible explanations include the action of a dopamine infusion to reduce the release of hormones from the anterior pituitary gland, such as prolactin, through stimulation of the $\mathrm{DA}_{2}$ receptor, which can have important immunoprotective effects, and inhibition of thyrotropin releasing hormone release. Adult data favors the use of norepinephrine as a first line agent in fluid-refractory vasodilated (and often hypotensive) septic shock (167-170). Although the majority of adults with fluid-refractory, dopamine-resistant shock have high $\mathrm{CO}$ and low SVR, children with this condition predominantly have low CO.

Dobutamine- or dopamine-refractory low CO shock may be reversed with epinephrine infusion $(29,171-174)$. Epinephrine is more commonly used in children than in adults. Some members of the committee recommended use of low-dose epinephrine as a first-line choice for cold hypodynamic shock. It is clear that epinephrine has potent inotropic and chronotropic effects, but its effects on peripheral vascular resistance and the endocrine stress response may result in additional problems. At lower infusion doses $(<0.3 \mu / \mathrm{kg} / \mathrm{min})$ epinephrine has greater beta-2-adrenergic effects in the peripheral vasculature with little alpha-adrenergic effect so that SVR falls, particularly in the skeletal musculature and skin. This may redirect blood flow away from the splanchnic circulation even though blood 
pressure and $\mathrm{CO}$ increases. This effect of epinephrine likely explains the observation that epinephrine transiently reduces gastric intramucosal $\mathrm{pH}$ in adults and animals with hyperdynamic sepsis (175), but there are no data available to evaluate whether gut injury does or does not occur with epinephrine use in children. Epinephrine stimulates gluconeogenesis and glycogenolysis, and inhibits the action of insulin, leading to increased blood glucose concentrations. In addition, as part of the stimulation of gluconeogenesis, epinephrine increases the shuttle of lactate to the liver as a substrate for glucose production (the Cori cycle). Thus, patients on epinephrine infusion have increased plasma lactate concentrations independent of changes in organ perfusion, making this parameter somewhat more difficult to interpret in children with septic shock.

Ideally, epinephrine should be administered by a secure central venous route, but in an emergency it may be infused through a peripheral IV route or through an intraosseous needle while attaining central access. The American Heart Association/PALS guidelines for children recommends the initial use of epinephrine by peripheral IV or interosseous for cardiopulmonary resuscitation or post-cardiopulmonary resuscitation shock, and by the intramuscular route for ana-phylaxis (176). Even though a common perception, there is no data clarifying if the peripheral infiltration of epinephrine produces more local damage than observed with dopamine. The severity of local symptoms likely depends on the concentration of the vasoactive drug infusion and the duration of the peripheral infiltration before being discovered. If peripheral infiltration occurs with any cat-echolamine, its adverse effects may be antagonized by local subcutaneous infiltration with phentolamine, 1$5 \mathrm{mg}$ diluted in $5 \mathrm{~mL}$ of normal saline.

\section{Vasodilators}

When pediatric patients are normotensive with a low CO and high SVR, initial treatment of fluid-refractory patients consists of the use of an inotropic agent such as epinephrine or dobutamine that tends to lower SVR. In addition, a short-acting vasodilator may be added, such as sodium nitroprusside or nitro-glycerin to recruit microcirculation (177-182) and reduce ventricular afterload resulting in better ventricular ejection and global $\mathrm{CO}$, particularly when ventricular function is impaired. Orthogonal polarizing spectroscopy showed that addition of systemic IV nitroglycerin to dopamine/norepinephrine infusion restored tongue microvascular blood flow during adult septic shock (183). Nitrova-sodilators can be titrated to the desired effect, but use of nitroprusside is limited if there is reduced renal function secondary to the accumulation of sodium thiocyanate; use of nitroglycerin may also have limited utility over time through the depletion of tissue thiols that are important for its vasodilating effect. Other vasodilators that have been used in children include prostacyclin, pentoxifylline, dopexamine, and fenoldopam (184-189).

An alternative approach to improve cardiac contractility and lower SVR is based on the use of type III phosphodiesterase inhibitors (PDEIs) (190-196). This class of agents, which includes milrinone and inamrinone (formerly amrinone, but the name was changed to avoid confusion with amiodarone), has a synergistic effect with beta-adrenergic agonists since the latter agents stimulate intracellular cyclic adenosine monophosphate (cAMP) production, whereas the PDEIs increase intracellular cAMP by blocking its hydrolysis. Because the 
PDEIs do not depend on a receptor mechanism, they maintain their action even when the beta-adrenergic receptors are down-regulated or have reduced functional responsiveness. The main limitation of these agents is their need for normal renal function (for milrinone clearance) and liver function (for inamrinone clearance). Inamrinone and milrinone are rarely used in adults with septic shock because catecholamine refractory low $\mathrm{CO}$ and high vascular resistance is uncommon; however, this hemodynamic state represents a major proportion of children with fluid-refractory, dopamine-resistant shock. Fluid boluses are likely to be required if inamrinone or milrinone are administered with full loading doses. Because milrinone and inamrinone have long half lifes (1-10 hrs depending on organ function) it can take 3-30 hrs to reach $90 \%$ of steady state if no loading dose is used. Although recommended in the literature some individuals in the committee choose not to use boluses of inamrinone or milrinone. This group administers the drugs as a continuous infusion only. Other members divide the bolus in five equal aliquots administering each aliquot over 10 mins if blood pressure remains within an acceptable range. If blood pressure falls, it is typically because of the desired vasodilation and can be reversed by titrated (e.g., $5 \mathrm{~mL} / \mathrm{kg}$ ) boluses of isotonic crystalloid or colloid. Because of the long elimination half-life, these drugs should be discontinued at the first sign of arrhythmia, or hypotension caused by excessively diminished SVR. Hypotension-related toxicity can also be potentially overcome by beginning norepinephrine or vasopressin. Norepinephrine counteracts the effects of increased cAMP in vascular tissue by stimulating the alpha receptor resulting in vasoconstriction. Norepinephrine has little effect at the vascular $\beta_{2}$ receptor.

Rescue from refractory shock has been described in case reports and series using two medications with type III phosphodiesterase activity. Levosimendan is a promising new medication that increases $\mathrm{Ca}^{++}$/actin/tropomyosin complex binding sensitivity and also has some type III PDEI and adenosine triphosphate-sensitive $\mathrm{K}^{+}$channel activity. Because one of the pathogenic mechanisms of endotoxin-induced heart dysfunction is desensitization of $\mathrm{Ca}^{++} /$actin/tropomyosin complex binding (197-202), this drug allows treatment at this fundamental level of signal transduction overcoming the loss of contractility that characterizes septic shock. Enoximone is a type III PDEI with 10 times more $\beta_{1}$ cAMP hydrolysis inhibition than $\beta_{2}$ cAMP hydrolysis inhibition (203-205). Hence, it can be used to increase cardiac performance with less risk of undesired hypotension.

\section{Vasopressor Therapy}

Dopamine remains the first-line vasopressor for fluid-refractory hypotensive shock in the setting of low SVR. However, there is some evidence that patients treated with dopamine have a worse outcome than those treated without dopamine (206) and that norepinephrine, when used exclusively in this setting, leads to adequate outcomes (168). There is also literature demonstrating an age-specific insensitivity to dopamine (207-216). Dopamine causes vasoconstriction by releasing norepinephrine from sympathetic vesicles as well as acting directly on alpha-adrenergic receptors. Immature animals and young humans $(<6$ months) may not have developed their full component of sympathetic innervation so they have reduced releasable stores of norepinephrine. Dopamine-resistant shock commonly responds to norepinephrine or high-dose epinephrine (29, 217-219). Some committee members advocate the use of low-dose norepinephrine as a first-line agent for fluid- 
refractory hypotensive hyperdynamic shock. Based on experimental and clinical data, norepinephrine is recommended as the first-line agent in adults with fluid-refractory shock. If the patient's clinical state is characterized by low SVR (e.g., wide pulse pressure with DBP that is less than one-half the systolic pressure), norepinephrine is recommended alone. Other experts have recommended combining norepinephrine with dobutamine, recognizing that dobutamine is a potent inotrope that has intrinsic vasodilating action that may be helpful to counteract excessive vasoconstriction from norepinephrine. Improved capillary and gut blood flow were observed in animal and human studies with norepinephrine plus dobutamine in comparison with high-dose dopamine or epinephrine.

Vasopressin has been shown to increase MAP, SVR, and urine output in patients with vasodilatory septic shock and hyporesponsiveness to catecholamines (167, 220-229). Vasopressin's action is independent of catecholamine receptor stimulation, and therefore its efficacy is not affected by alpha-adrenergic receptor down-regulation often seen in septic shock. Terlipressin, a long acting form of vasopressin, has been reported to reverse vasodilated shock as well $(228,230)$.

Although angiotensin can also be used to increase blood pressure in patients who are refractory to norepinephrine, its clinical role is not as well defined (231). Phenylephrine is another pure vasopressor with no beta-adrenergic activity (232). Its clinical role is also limited since it may improve blood pressure but reduce blood flow through its action to increase SVR. Vasopressors can be titrated to end points of perfusion pressure (MAP-central venous pressure) or SVR that promote optimum urine output and creatinine clearance (69, $71,217,218)$, but excessive vasoconstriction compromising micro-circulatory flow should be avoided. NO inhibitors and methylene blue are considered investigational therapies (233235). Studies have shown an increased mortality with nonselective NO synthase inhibitors suggesting that simply increasing blood pressure through excessive vasoconstriction has adverse effects (138). Low-dose arginine vasopressin (in doses $\$ 0.04$ units $/ \mathrm{kg} / \mathrm{min}$ ) as an adjunctive agent has short-term hemodynamic benefits in adults with vasodilatory shock. It is not currently recommended for treatment of cardiogenic shock, hence it should not be used without $\mathrm{Scv}_{2} / \mathrm{CO}$ monitoring. The effect of low-dose arginine vasopressin on clinically important outcomes such as mortality remains uncertain. The Vasopressin and Septic Shock Trial, a randomized controlled clinical trial that compared low-dose arginine vasopressin with norepinephrine in patients with septic shock, showed no difference between regimens in the 28-day mortality primary end point (236). The safety and efficacy of low-dose arginine vasopressin have yet to be demonstrated in children with septic shock, and await the results of an ongoing randomized controlled trial $(237,238)$.

Glucose, Calcium, Thyroid, and Hydrocortisone Replacement-It is important to maintain metabolic and hormonal homeostasis in newborns and children. Hypoglycemia can cause neurologic devastation when missed. Therefore, hypoglycemia must be rapidly diagnosed and promptly treated. Required glucose infusion rates for normal humans are age specific but can be met by delivering a D10\%-containing solution at maintenance fluid rates $(8 \mathrm{mg} / \mathrm{kg} / \mathrm{min}$ glucose in newborns, $5 \mathrm{mg} / \mathrm{kg} / \mathrm{min}$ glucose in children, and $2 \mathrm{mg} / \mathrm{kg} / \mathrm{min}$ in adolescents). Patients with liver failure will require higher glucose infusion rates (up to 16 $\mathrm{mg} / \mathrm{kg} / \mathrm{min}$ ). Hyperglycemia is also a risk factor for mortality. Lin and Carcillo (239) 
reported that children with septic shock, who had hyperglycemia (>140 mg/dL) and an elevated anion gap, showed resolution of their anion gap when insulin was added to their glucose regimen. This was associated with reversal of catabolism as measured by urinary organic acids. Infants with metabolic disease are particularly vulnerable to cata-bolic failure and must be treated with appropriate glucose delivery, and when needed insulin to assure glucose uptake, during septic shock. It is important to note that insulin requirements decrease at approximately $18 \mathrm{hrs}$ after the onset of shock. Infusion of insulin and glucose are also effective inotropes. Two members of the task force preferred using D5\%-containing solution for patients with hyperglycemia. Greater than $90 \%$ of the committee agreed with meeting glucose requirements and treating hyperglycemia with insulin. Hypocalcemia is a frequent, reversible contributor to cardiac dysfunction as well $(56,240,241)$. Calcium replacement should be directed to normalize ionized calcium concentration. One member of the task force did not agree that calcium replacement should be given for hypocalcemia. All agreed that care should be taken to not overtreat as calcium toxicity may occur with elevated concentrations.

Replacement with thyroid and/or hydrocortisone can also be lifesaving in children with thyroid and/or adrenal insufficiency and catecholamine-resistant shock (29, 55, 242-260). Infusion therapy with triiodothyronine has been beneficial in postoperative congenital heart disease patients but has yet to be studied in children with septic shock (253).

Hypothyroidism is relatively common in children with trisomy 21 and children with central nervous system pathology (e.g., pituitary abnormality). Unlike adults, children are more likely to have absolute adrenal insufficiency defined by a basal cortisol $<18 \mu \mathrm{g} / \mathrm{dL}$ and a peak adrenocorticotropic hormone (ACTH)-stimulated cortisol concentration $<18 \mu \mathrm{g} / \mathrm{dL}$. Nonsurvivors have exceedingly high ACTH/cortisol ratios within the first 8 hrs of meningococcal shock (206). Aldosterone levels are also markedly depressed in meningococcemia (261). Patients at risk of inadequate cortisol/aldosterone production in the setting of shock include children with purpura fulminans and Waterhouse-Friderichsen syndrome, children who previously received steroid therapies for chronic illness, and children with pituitary or adrenal abnormalities. Review of the pediatric literature found case series $(251,252)$ and randomized trials $(242,243)$ that used "shock dose" hydrocortisone in children. The first randomized controlled trial showed improved outcome with hydrocortisone therapy in children with dengue shock. The second study was underpowered and showed no effect of hydrocortisone therapy on outcome in children with dengue shock. The reported shock dose of hydrocortisone is 25 times higher than the stress dose $(242,243$, 247, 248, 250-252, 258, 259). At present the committee makes no changes from the 2002 recommendation. The committee only recommends hydrocortisone treatment for patients with absolute adrenal insufficiency (peak cortisol concentration attained after corticotropin stimulation $<18 \mu \mathrm{g} / \mathrm{dL}$ ) or adrenal-pituitary axis failure and catecholamine-resistant shock. Some support the use of stress dose only whereas others support the use of shock dosage when needed. In the absence of any new studies shedding light on the subject since 2002, the dose can be titrated to resolution of shock using between $2 \mathrm{mg} / \mathrm{kg}$ and $50 \mathrm{mg} / \mathrm{kg} / \mathrm{day}$ as a continuous infusion or intermittent dosing if desired. The treatment should be weaned off as tolerated to minimize potential long-term toxicities. 
Administration of prolonged hydrocortisone and fludrocortisone $(6 \mathrm{mg} / \mathrm{kg} /$ day cortisol equivalent $\times 7$ days) had been recommended for adults with dopamine-resistant septic shock and relative adrenal insufficiency (basal cortisol $>18 \mu \mathrm{g} / \mathrm{dL}$ with cortisol increment after corticotropin stimulation $<9 \mu \mathrm{g} / \mathrm{dL})(260)$; however, adult guidelines now recommend this therapy for any adult with dopamine-resistant septic shock. The continuing debate on whether this should similarly be an adjunctive therapy for pediatric sepsis will likely only be resolved with yet-to-be done pediatric trials. Since 2002, a randomized trial of a 7-day course of $3 \mathrm{mg} / \mathrm{kg} /$ day of intermittent hydrocortisone therapy for dopamine-treated septic shock in premature babies was performed. These babies had reduced dopamine requirements but no improvement in mortality $(58,262,264)$. Unlike dexamethasone, which was associated with neurologic consequences in premature babies (261), hydrocortisone did not cause similar complications in premature babies (263).

Multiple pediatric studies conducted over the interval 1999-2006 provide consistent evidence that children who succumbed from septic shock exhibited lower cortisol levels than those who survived, and that septic shock nonsurvivors had lower random plasma cortisol concentrations compared with septic shock survivors; the latter had lower random plasma cortisol concentrations compared with sepsis survivors $(254,255,265-267)$. This effect is not attributable to inadequate ACTH adrenal stimulation; on the contrary, an opposite trend prevails, namely septic shock nonsurvivors exhibit high circulating ACTH concentrations compared with septic shock survivors, who in turn have higher circulating ACTH concentrations compared with patients with sepsis. One retrospective cohort study using the Pediatric Health Information System database examined factors associated with outcome in children with severe sepsis as operationally identified by a combination of infection plus need for a vasoactive infusion and mechanical ventilation (268). Among 6693 children meeting the definition of severe sepsis, mortality was $30 \%$ for children who received steroids compared with $18 \%$ for those who did not (crude odds ratio 1.9) (95\% confidence interval 1.7-2.2). An important liability of this investigation relates to lack of illness severity data. Although steroids may have been given preferentially to more severely ill children, their use was associated with increased mortality. Steroid use was linked to disseminated candidiasis in a case report (269). The committee continues to maintain equipoise on the question of adjunctive steroid therapy for pe-diatric sepsis (outside of classic adrenal or hypophyseal pituitary axis (HPA) axis insufficiency), pending prospective randomized clinical trials.

Persistent Pulmonary Artery Hypertension of the Newborn Therapy-Inhaled NO therapy is the treatment of choice for uncomplicated PPHN $(270,271)$. However, metabolic alkalinization remains an important initial resuscitative strategy during shock because PPHN can reverse when acidosis is corrected (272). For centers with access to inhaled NO, this is the only selective pulmonary vasodilator reported to be effective in reversal of PPHN (270, 271, 273-278). Milrinone or inamrinone may be added to improve heart function as tolerated (279-281). ECMO remains the therapy of choice for patients with refractory PPHN and sepsis (282-285). New investigations support use of inhaled iloprost (synthetic analog of prostacyclin) or adenosine infusion as modes of therapy for PPHN (286-291). 
Extracorporeal Therapies-ECMO is not routinely used in adults (with the notable exception of the University of Michigan) (282). ECMO is a viable therapy for refractory septic shock in neonates (283) and children because neonates (approximately $80 \%$ survival) and children (approximately 50\% survival) (292-295) have the same outcomes whether the indication for ECMO is refractory respiratory failure or refractory shock from sepsis or not. It is also effective in adult hantavirus victims with low CO/high SVR shock $(296,297)$.

Although ECMO survival is similar in pediatric patients with and without sepsis, thrombotic complications can be more common in sepsis. Efforts are warranted to reduce ECMOinduced hemolysis because free heme scavenges NO, adenosine, and a disintegrin and metalloprotease with thrombospondin motifs-13 (ADAMTS-13; von Willebrand factor cleaving protease) leading to microvascular thrombosis, reversal of portal blood flow and multiple organ failure $(298,299)$. Nitroglycerin (NO donor), adenosine, and fresh frozen plasma (FFP) (ADAMTS-13) can be in-fused to attempt to neutralize these effects. Hemolysis can be avoided, in part, by using the proper-sized cannula for age and limiting ECMO total blood flow to no greater than $110 \mathrm{~mL} / \mathrm{kg} / \mathrm{min}$. Additional CO can be attained using inotrope/ vaspodilator therapies.

Investigators also reported that the use of high flux CRRT $(>35 \mathrm{~mL} / \mathrm{kg} / \mathrm{h}$ filtration-dialysis flux), with concomitant FFP or antithrombotic protein $\mathrm{C}$ infusion to reverse prolonged INR without causing fluid overload, reduced inotrope/vaso-pressor requirements in children with refractory septic shock and purpura $(7,15,300-305)$. The basis of this beneficial effect remains unknown. It could result from prevention of fluid overload, clearance of lactate and organic acids, binding of inflammatory mediators, reversal of coagulopathy, or some combination of these actions.

\section{RECOMMENDATIONS}

\section{Pediatric Septic Shock}

Diagnosis-The inflammatory triad of fever, tachycardia, and vasodilation are common in children with benign infections (Fig. 1). Septic shock is suspected when children with this triad have a change in mental status manifested as irritability, inappropriate crying, drowsiness, confusion, poor interaction with parents, lethargy, or becoming unarousable. The clinical diagnosis of septic shock is made in children who 1) have a suspected infection manifested by hypothermia or hyperthermia, and 2) have clinical signs of inadequate tissue perfusion including any of the following; decreased or altered mental status, prolonged capillary refill > 2 secs (cold shock), diminished pulses (cold shock) mottled cool extremities (cold shock) or flash capillary refill (warm shock), bounding peripheral pulses, and wide pulse pressure (warm shock) or decreased urine output $<1 \mathrm{ml} / \mathrm{kg} / \mathrm{h}$. Hypotension is not necessary for the clinical diagnosis of septic shock; however, its presence in a child with clinical suspicion of infection is confirmatory.

\section{ABCs: The First Hour of Resuscitation (Emergency Room Resuscitation)}

Goals: (Level III)—Maintain or restore airway, oxygenation, and ventilation (Table 1); maintain or restore circulation, defined as normal perfusion and blood pressure; maintain or restore threshold HR. 
Therapeutic End Points (Level III)—Capillary refill $\_$secs, normal pulses with no differential between the quality of peripheral and central pulses, warm extremities, urine output $>1 \mathrm{~mL} / \mathrm{kg} / \mathrm{h}$, normal mental status, normal blood pressure for age (noninvasive blood pressure only reliable when pulses palpable), normal glucose concentration, normal ionized calcium concentration.

Monitoring (Level III)—Pulse oximeter, continuous electrocardiography, blood pressure and pulse pressure. Note pulse pressure and diastolic pressure to help distinguish between low SVR (wide pulse pressure due to low DBP) and high SVR (narrow pulse pressure). Temperature, urine output, glucose, ionized calcium.

Airway and Breathing (Level III)—Airway and breathing should be rigorously monitored and maintained. Lung compliance and work of breathing may change precipitously. In early sepsis, patients often have a respiratory alkalosis from centrally mediated hyperventilation. As sepsis progresses, patients may have hypoxemia as well as metabolic acidosis and are at high risk to develop respiratory acidosis secondary to a combination of parenchymal lung disease and/or inadequate respiratory effort due to altered mental status. The decision to intubate and ventilate is based on clinical assessment of increased work of breathing, hypoventilation, or impaired mental status. Waiting for confirmatory laboratory tests is discouraged. Up to $40 \%$ of CO is used for work of breathing. Therefore, intubation and mechanical ventilation can reverse shock. If possible, volume loading and peripheral or central inotropic/vasoactive drug support is recommended before and during intubation because of relative or absolute hypovolemia, cardiac dysfunction, and the risk of suppressing endogenous stress hormone response with agents that facilitate intubation. Etomidate is not recommended. Ketamine with atropine pretreatment and benzodiazepine postintubation can be used as a sedative/induction regimen of choice to promote cardiovascular integrity. A short-acting neuromuscular blocker can facilitate intubation if the provider is confident she/he can maintain airway patency.

Circulation (Level II)_-Vascular access should be rapidly attained. Establish intraosseous access if reliable venous access cannot be attained in minutes. Fluid resuscitation should commence immediately unless hepatomegaly/rales are present. Recall that rales may be heard in children with pneumonia as a cause of sepsis, so it does not always imply that the patient is fluid overloaded. If pneumonia is suspected or confirmed, fluid resuscitation should proceed with careful monitoring of the child's work of breathing and oxygen saturation. In the fluid-refractory patient, begin a peripheral inotrope (low-dose dopamine or epinephrine) if a second peripheral IV/intraosseus catheter is in place, while establishing a central venous line. When administered through a peripheral IV/intraosseus catheter, the inotrope should be infused either as a dilute solution or with a second carrier solution running at a flow rate to assure that it reaches the heart in a timely fashion. Care must be taken to reduce dosage if evidence of peripheral infiltration/ischemia occurs as alphaadrenergic receptor-mediated effects occur at higher concentrations for epinephrine and dopamine. Central dopamine, epinephrine, or norepinephrine can be administered as a first line drug as indicated by hemodynamic state when a central line is in place. It is generally 
appropriate to begin central venous infusion and wait until a pharmacologic effect is observed before stopping the peripheral infusion.

Fluid Resuscitation (Level II)—Rapid fluid boluses of $20 \mathrm{~mL} / \mathrm{kg}$ (isotonic crystalloid or $5 \%$ albumin) can be administered by push or rapid infusion device (pressure bag) while observing for signs of fluid overload (i.e., the development of increased work of breathing, rales, gallop rhythm, or hepatomegaly). In the absence of these clinical findings, repeated fluid boluses can be administered to as much as $200 \mathrm{~mL} / \mathrm{kg}$ in the first hour. Children commonly require $40-60 \mathrm{~mL} / \mathrm{kg}$ in the first hour. Fluid can be pushed with the goal of attaining normal perfusion and blood pressure. Hypoglycemia and hypocalcemia should be corrected. A D10\%-containing isotonic IV solution can be run at maintenance IV fluid rates to provide age appropriate glucose delivery and to prevent hypoglycemia.

Hemodynamic Support (Level II)—Central dopamine may be titrated through central venous access. If the child has fluid refractory/dopamine resistant shock, then central epinephrine can be started for cold shock $(0.05-0.3 \mu \mathrm{g} / \mathrm{kg} / \mathrm{min})$ or norepinephrine can be titrated for warm shock to restore normal perfusion and blood pressure.

Hydrocortisone Therapy (Level III)_-If a child is at risk of absolute adrenal insufficiency or adrenal pituitary axis failure (e.g., purpura fulminans, congenital adrenal hyperplasia, prior recent steroid exposure, hypothalamic/pituitary abnormality) and remains in shock despite epinephrine or norepinephrine infusion, then hydrocortisone can be administered ideally after attaining a blood sample for subsequent determination of baseline cortisol concentration. Hydrocortisone may be administered as an intermittent or continuous infusion at a dosage which may range from $1-2 \mathrm{mg} / \mathrm{kg} /$ day for stress coverage to 50 $\mathrm{mg} / \mathrm{kg} /$ day titrated to reversal of shock.

\section{Stabilization: Beyond the First Hour (Pediatric Intensive Care Unit Hemodynamic Support)}

Goals: (Level III)—Normal perfusion; capillary refill $\mathcal{S}$ secs, threshold HRs. perfusion pressure (MAP-central venous pressure, or MAP-IAP) appropriate for age. $\mathrm{ScvO}_{2}>70 \%$; CI $>3.3 \mathrm{~L} / \mathrm{min} / \mathrm{m}^{2}$ and $<6.0 \mathrm{~L} / \mathrm{min} / \mathrm{m}^{2}$.

Therapeutic End Points: (Level III)—Capillary refill $\_$secs, threshold HRs, normal pulses with no differential between the quality of the peripheral and central pulses, warm extremities, urine output $>1 \mathrm{~mL} / \mathrm{kg} / \mathrm{h}$, normal mental status, $\mathrm{CI}>3.3$ and $<6.0 \mathrm{~L} / \mathrm{min} / \mathrm{m}^{2}$ with normal perfusion pressure (MAP-central venous pressure, or MAP-IAP) for age, $\mathrm{Scvo}_{2}$ >70\%; maximize preload to maximize CI, MAP - central venous pressure; normal INR, anion gap, and lactate.

Monitoring (Level III)—Pulse oximetry, continuous electrocardiogram, continuous intraarterial blood pressure, temperature (core), urine output, central venous pressure/ $\mathrm{O}_{2}$ saturation and/or pulmonary artery pressure/ $\mathrm{O}_{2}$ saturation, $\mathrm{CO}$, glucose and calcium, INR, lactate, and anion gap.

Fluid Resuscitation (Level II)—Fluid losses and persistent hypovolemia secondary to diffuse capillary leak can continue for days. Ongoing fluid replacement should be directed at 
clinical end points including perfusion, central venous pressure, echocardiographic determination of end-diastolic volume, pulmonary capillary wedge pressure/end-diastolic volume (when available), and CO. Crystalloid is the fluid of choice in patients with hemoglobin $>10 \mathrm{~g} / \mathrm{dL}$. Red blood cell transfusion can be given to children with hemoglobin $<10 \mathrm{~g} / \mathrm{dL}$. FFP is recommended for patients with prolonged INR but as an infusion, not a bolus. After shock resuscitation, diuretics/peritoneal dialysis/ high flux CRRT can be used to remove fluid in patients who are $10 \%$ fluid overloaded and unable to maintain fluid balance with native urine output/extrarenal losses.

Elevated lactate concentration and anion gap measurement can be treated by assuring both adequate oxygen delivery and glucose utilization. Adequate oxygen delivery (indicated by a $\mathrm{Scvo}_{2}>70 \%$ ) can be achieved by attaining hemoglobin $\geq 10 \mathrm{~g} / \mathrm{dL}$ and $\mathrm{CO}>3.3 \mathrm{~L} / \mathrm{min} / \mathrm{m}^{2}$ using adequate volume loading and inotrope/ vasodilator support when needed (as described below). Appropriate glucose delivery can be attained by giving a D10\% containing isotonic IV solution at fluid maintenance rate. Appropriate glucose uptake can be attained in subsequently hyperglycemic patients by titrating an insulin infusion to reverse hyperglycemia (keep glucose concentration $\unlhd 50 \mathrm{mg} / \mathrm{dL}$ ) while carefully monitoring to avoid hypoglycemia (keep glucose concentration $280 \mathrm{mg} / \mathrm{dL}$ ). The use of lesser glucose infusion rates (e.g., D5\% or lower volumes of D10\%) will not provide glucose delivery requirements.

Hemodynamic support (Level II)—Hemodynamic support can be required for days in children with fluid-refractory dopamine resistant shock. Children with catecholamine resistant shock can present with low CO/high SVR, high CO/ low SVR, or low CO/low SVR shock. Although children with persistent shock commonly have worsening cardiac failure, hemodynamic states may completely change with time. A pulmonary artery, pulse index contour cardiac output, or femoral artery thermodilution catheter, or Doppler ultrasound should be used when poor perfusion, including reduced urine output, acidosis, or hypotension persists despite use of hemodynamic therapies guided by clinical examination, blood pressure analysis, and arterial and $\mathrm{Scvo}_{2}$ analysis. Children with catecholamineresistant shock can respond to a change in hemodynamic therapeutic regimen with resolution of shock. Therapies should be directed to maintain mixed venous $/ \mathrm{Scvo}_{2}>70 \%$, CI $>3.3 \mathrm{~L} / \mathrm{min} / \mathrm{m}^{2}<6.0 \mathrm{~L} / \mathrm{min} / \mathrm{m}^{2}$, and a normal perfusion pressure for age (MAP-central venous pressure).

\section{Shock with Low Cl, Normal Blood Pressure, and High Systemic Vascular Resistance (Level II)—This clinical state is similar to that seen in a child with} cardiogenic shock in whom afterload reduction is a mainstay of therapy designed to improve blood flow by reducing ventricular afterload and thus increasing ventricular emptying. Thus, nitroprusside or nitroglycerin is first line vasodilators in patients with epinephrine-resistant septic shock and normal blood pressure. If cyanide or isothiocyanate toxicity develops from nitroprusside, or methemoglobin toxicity develops from nitroglycerin, or there is a continued low CO state, then the clinician should substitute milrinone or inamrinone. As noted above, the long elimination half-life of these drugs can lead to slowly reversible toxicities (hypotension, tachyarrhythmias, or both) particularly if abnormal renal or liver function 
exists. Such toxicities can be reversed, in part, with norepinephrine or vasopressin infusion. Additional volume loading may be necessary to prevent hypotension when loading doses of milrinone or inamrinone are used. Levosimendan and enoximone may have a role in recalcitrant low CO syndrome. Thyroid replacement with triiodothyronine is warranted for thyroid insufficiency, and hydrocortisone replacement can be warranted for adrenal or hypothalamic-pituitary-adrenal axis insufficiency.

\section{Shock with Low Cl, Low Blood Pressure, and Low Systemic Vascular} Resistance (Level II)-Norepinephrine can be added to epinephrine to increase DBP and SVR. Once an adequate blood pressure is achieved, dobutamine, type III PDEI (particularly enoximone, which has little vasodilatory properties), or levosimendan can be added to norepinephrine to improve $\mathrm{CI}$ and $\mathrm{ScvO}_{2}$. Thyroid replacement with triiodothyronine is warranted for thyroid insufficiency, and hydrocortisone replacement is warranted for adrenal or hypothalamic-pituitary-adrenal axis insufficiency.

\section{Shock with High Cl and Low Systemic Vascular Resistance (Level II)-When} titration of norepinephrine and fluid does not resolve hypotension, then low dose vasopressin, angiotensin, or terlipressin can be helpful in restoring blood pressure; however, these potent vasoconstrictors can reduce $\mathrm{CO}$, therefore it is recommended that these drugs are used with $\mathrm{CO} / \mathrm{ScVO}_{2}$ monitoring. In this situation, additional inotropic therapies may be required, such as low-dose epinephrine or dobutamine, or the vasopressor infusion may be reduced. Terlipressin is a longer-acting drug than angiotensin or vasopressin so toxicities are more long acting. As with other forms of severe shock, thyroid hormone or adrenocortical replacement therapy may be added for appropriate indications.

Refractory Shock (Level II)—Children with refractory shock must be suspected to have one or more of the following sometimes occult morbidities (treatment in parenthesis), including pericardial effusion (pericardiocentesis), pneumothorax (thoracentesis), hypoadrenalism (adrenal hormone replacement), hypothyroidism (thyroid hormone replacement), ongoing blood loss (blood replacement/hemostasis), increased IAP (peritoneal catheter, or abdominal release), necrotic tissue (nidus removal), inappropriate source control of infection (remove nidus and use antibiotics with the lowest minimum inhibitory concentration possible, preferably <1, use IV immunoglobulin for toxic shock), excessive immunosuppression (wean immunesuppressants), or immune compromise (restore immune function; e.g., white cell growth factors/transfusion for neutropenic sepsis). When these potentially reversible causes are addressed, ECMO becomes an important alternative to consider. Currently, however, the expected survival with ECMO is no greater than $50 \%$. If the clinician suspects that outcome will be better with ECMO, flows greater than 110 $\mathrm{mL} / \mathrm{kg} / \mathrm{min}$ should be discouraged as they may be associated with hemolysis. Measure free hemoglobin and maintain concentration $<10 \mu \mathrm{g} / \mathrm{dL}$ by using adequate catheter, circuit, and oxygenator sizes for age. Calcium concentration should be normalized in the red blood cell pump prime (usually requires $300 \mathrm{mg} \mathrm{CaCl} 2$ per unit of packed red blood cells). Additional venous access may be required if ECMO flow is $<110 \mathrm{~mL} / \mathrm{kg} / \mathrm{min}$ with a negative pressure $<-25 \mathrm{~mm} \mathrm{Hg}$. This may require the addition of intrathoracic drainage as well. Cannula placement should be checked using both chest radiograph and ultrasound guidance. High 
flux CRRT ( $>35 \mathrm{~mL} / \mathrm{kg} / \mathrm{h}$ ) should also be considered, particularly in patients at risk for fluid overload, with septic shock and purpura. This extracorporeal therapy can reduce inotrope/ vasopressor needs within $6 \mathrm{hrs}$ of use.

\section{Newborn Septic Shock}

Diagnosis-Septic shock should be suspected in any newborn with tachycardia, respiratory distress, poor feeding, poor tone, poor color, tachypnea, diarrhea, or reduced perfusion, particularly in the presence of a maternal history of chorioamnionitis or prolonged rupture of membranes (Fig. 2). It is important to distinguish newborn septic shock from cardiogenic shock caused by closure of the patent ductus arteriosus in newborns with ductaldependent complex congenital heart disease. Any newborn with shock and hepatomegaly, cyanosis, a cardiac murmur, or differential upper and lower extremity blood pressures or pulses should be started on prostaglandin infusion until complex congenital heart disease is ruled out by echocardiographic analysis. Inborn errors of metabolism resulting in hyperammonemia or hypoglycemia may simulate septic shock and appropriate laboratory tests should be obtained to rule out these conditions. Newborn septic shock is typically accompanied by increased pulmonary vascular resistance and artery pressures. PPHN can cause right ventricle failure with right to left shunting at the atrial/ductal levels causing cyanosis.

\section{ABCs: The First Hour of Resuscitation (Delivery Room Resuscitation)}

Goals: (Level III)-Maintain airway, oxygenation, and ventilation; restore and maintain circulation, defined as normal perfusion and blood pressure; maintain neonatal circulation; and maintain threshold HRs.

Therapeutic End Points (Level III)—Capillary refill $\_$secs, normal pulses with no differential in quality between peripheral and central pulses, warm extremities, urine output $>1 \mathrm{~mL} / \mathrm{kg} / \mathrm{h}$, normal mental status, normal blood pressure for age, normal glucose, and calcium concentrations.

Difference in preductal and postductal $\mathrm{O}_{2}$ saturation $<5 \%$.

95\% arterial oxygen saturation.

Monitoring (Level III)-Temperature, preductal and postductal pulse oximetry, intraarterial (umbilical or peripheral) blood pressure, continuous electrocardiogram, blood pressure, arterial $\mathrm{pH}$, urine output, and glucose, ionized calcium concentration.

Airway and Breathing (Level III)_Airway patency and adequate oxygenation and ventilation should be rigorously monitored and maintained. The decision to intubate and ventilate is based on clinical diagnosis of increased work of breathing, inadequate respiratory effort, marked hypoxemia, or a combination of these abnormalities. Volume loading is often necessary before intubation and ventilation because positive pressure ventilation can reduce preload. 
Circulation (Level III)—Vascular access can be rapidly attained according to neonatal resuscitation program guidelines. Placement of an umbilical arterial and venous line is preferred.

Fluid Resuscitation (Level II)-Fluid boluses of $10 \mathrm{~mL} / \mathrm{kg}$ can be administered, observing for the development of hepatomegaly and increased work of breathing. Up to 60 $\mathrm{mL} / \mathrm{kg}$ may be required in the first hour. Fluid should be infused with a goal of attaining normal perfusion and blood pressure. A D10\%-containing isotonic IV solution run at maintenance rate will provide age appropriate glucose delivery to prevent hypoglycemia.

Hemodynamic Support (Level II)—Patients with severe shock uniformly require cardiovascular support during fluid resuscitation. Although dopamine can be used as the first-line agent, its effect on pulmonary vascular resistance should be considered. A combination of dopamine at low dosage ( $<8 \mu \mathrm{g} / \mathrm{kg} / \mathrm{min}$ ) and dobutamine (up to $10 \mu \mathrm{g} / \mathrm{kg} /$ $\mathrm{min}$ ) is initially recommended. If the patient does not adequately respond to these interventions, then epinephrine $(0.05-0.3 \mu \mathrm{g} / \mathrm{kg} / \mathrm{min})$ can be infused to restore normal blood pressure and perfusion.

Persistent Pulmonary Hypertension Therapy (Level II)—Hyperoxygenate initially with $100 \%$ oxygen and institute metabolic alkalinization (up to $\mathrm{pH} 7.50$ ) with $\mathrm{NaHCO}_{3}$ or tromethamine until inhaled $\mathrm{NO}$ is available. Mild hyperventilation to produce a respiratory alkalosis can also be instituted until $100 \% \mathrm{O}_{2}$ saturation and $<5 \%$ difference in preductal and postductal saturations are obtained. Inhaled NO should be administered as the first treatment when available.

\section{Stabilization: Beyond the First Hour (Neonatal Intensive Care Unit Hemodynamic Support) \\ Goals: (Level III)—Restore and maintain threshold HR; maintain normal perfusion and blood pressure; maintain neonatal circulation; $\mathrm{ScvO}_{2}>70 \%$; CI $>3.3 \mathrm{~L} / \mathrm{min} / \mathrm{m}^{2}$; SVC flow $>40 \mathrm{~mL} / \mathrm{kg} / \mathrm{min}$.}

Therapeutic End points (Level III)—Capillary refill $\_$secs, normal pulses with no differential between peripheral and central pulses, warm extremities, urine output $>1$ $\mathrm{mL} / \mathrm{kg} / \mathrm{h}$, normal mental status, normal blood pressure for age.

$>95 \%$ arterial oxygen saturation.

$<5 \%$ difference in preductal and postductal arterial oxygen saturation.

$\mathrm{ScvO}_{2}>70 \%$.

Absence of right-to-left shunting, tricuspid regurgitation, or right ventricular failure on echocardiographic analysis.

Normal glucose and ionized calcium concentrations.

SVC flow $>40 \mathrm{~mL} / \mathrm{kg} / \mathrm{min}$. 
$\mathrm{CI}>3.3 \mathrm{~L} / \mathrm{min} / \mathrm{m}^{2}$.

Normal INR.

Normal anion gap and lactate.

Fluid overload $<10 \%$.

Monitoring (Level III)—Pulse oximetry, blood gas analysis, electrocardiogram, continuous intra-arterial blood pressure, temperature, glucose and calcium concentration, "ins and outs," urine output, central venous pressure/ $\mathrm{O}_{2}$ saturation, $\mathrm{CO}, \mathrm{SVC}$ flow, INR, and anion gap and lactate.

Fluid Resuscitation (Level II)—Fluid losses and persistent hypovolemia secondary to diffuse capillary leak can continue for days. Ongoing fluid replacement should be directed at clinical end points, including perfusion and central venous pressure. Crystalloid is the fluid of choice in neonates with hemoglobin $>12 \mathrm{~g} / \mathrm{dL}$. Packed red blood cells can be transfused in newborns with hemoglobin $<12 \mathrm{~g} / \mathrm{dL}$. Diuretics or CRRT is recommended in newborns who are $10 \%$ fluid overloaded and unable to attain fluid balance with native urine output/ extrarenal losses. A D10\%-containing isotonic IV solution run at maintenance rate can provide age appropriate glucose delivery to prevent hypoglycemia. Insulin infusion can be used to correct hyperglycemia. Diuretics are indicated in hypervolemic patients to prevent fluid overload.

Hemodynamic Support (Level II)-A 5-day, 6-hr per day course of IV pentoxifylline can be used to reverse septic shock in VLBW babies. In term newborns with PPHN, inhaled $\mathrm{NO}$ is often effective. Its greatest effect is usually observed at $20 \mathrm{ppm}$. In newborns with poor left ventricle function and normal blood pressure, the addition of nitrosovasodilators or type III phosphodiesterase inhibitors to epinephrine $(0.05-0.3 \mu \mathrm{g} / \mathrm{kg} / \mathrm{min})$ can be effective but must be monitored for toxicities. It is important to volume load based on clinical examination and blood pressure changes when using these systemic vasodilators. Triiodothyronine is an effective inotrope in newborns with thyroid insufficiency.

Norepinephrine can be effective for refractory hypotension but $\mathrm{ScvO}_{2}$ should be maintained $>70 \%$. An additional inotrope therapy should be added if warranted. Hydrocortisone therapy can be added if the newborn has adrenal insufficiency (defined by a peak cortisol after ACTH $<18 \mu \mathrm{g} / \mathrm{dL}$, or basal cortisol $<18 \mu \mathrm{g} / \mathrm{dL}$ in an appropriately volumeloaded patient requiring epinephrine). The rescue use of vasopressin, terlipressin, or angiotensin can be considered in the presence of adequate $\mathrm{CO}, \mathrm{SVC}$ flow, and/or $\mathrm{ScvO}_{2}$ monitoring.

\section{ECMO and CRRT Therapy for Refractory Shock (Level II)}

Newborns with refractory shock must be suspected to have unrecognized morbidities (requiring specific treatment) including pericardial effusion (pericardiocentesis), pneumothorax (thoracentesis), ongoing blood loss (blood replacement/ hemostasis), hypoadrenalism (hydrocortisone), hypothyroidism (triiodothyronine), inborn errors of metabolism (responsive to glucose and insulin infusion or ammonia scavengers), and/or cyanotic or obstructive heart disease (responsive to prostaglandin $\mathrm{E}_{1}$ ), or a critically large 
patent ductus arteriosus (patent ductus arteriosus closure). When these causes have been excluded, ECMO becomes an important therapy to consider in term newborns. The current ECMO survival rate for newborn sepsis is $80 \%$. Most centers accept refractory shock or a $\mathrm{PaO}_{2}<40 \mathrm{~mm} \mathrm{Hg}$ after maximal therapy to be sufficient indication for ECMO support. ECMO flows greater than $110 \mathrm{~mL} / \mathrm{kg}$ should be discouraged because hemolysis can ensue. With veno-venous ECMO, persistent hypotension and/or shock should be treated with dopamine/dobutamine or epinephrine. Inotrope requirements frequently diminish when veno-arterial ECMO is used but not always. Calcium concentration should be normalized in the red blood cell pump prime (usually requires $300 \mathrm{mg} \mathrm{CaCl} 2$ per unit of packed red blood cells). In newborns with inadequate urine output and $10 \%$ fluid overload despite diuretics, CRRT is best performed while on the ECMO circuit.

\section{Authors}

Joe Brierley, MD, Joseph A. Carcillo, MD, Karen Choong, MD, Tim Cornell, MD, Allan DeCaen, MD, Andreas Deymann, MD, Allan Doctor, MD, Alan Davis, MD, John Duff, MD, Marc-Andre Dugas, MD, Alan Duncan, MD, Barry Evans, MD, Jonathan Feldman, MD, Kathryn Felmet, MD, Gene Fisher, MD, Lorry Frankel, MD, Howard Jeffries, MD, Bruce Greenwald, MD, Juan Gutierrez, MD, Mark Hall, MD, Yong Y. Han, MD, James Hanson, MD, Jan Hazelzet, MD, Lynn Hernan, MD, Jane Kiff, MD, Niranjan Kissoon, MD, Alexander Kon, MD, Jose Irazusta, MD, John Lin, MD, Angie Lorts, MD, Michelle Mariscalco, MD, Renuka Mehta, MD, Simon Nadel, MD, Trung Nguyen, MD, Carol Nicholson, MD, Mark Peters, MD, Regina OkhuysenCawley, MD, Tom Poulton, MD, Monica Relves, MD, Agustin Rodriguez, MD, Ranna Rozenfeld, MD, Eduardo Schnitzler, MD, Tom Shanley, MD, Sara Skache, MD, Peter Skippen, MD, Adalberto Torres, MD, Bettina von Dessauer, MD, Jacki Weingarten, MD, Timothy Yeh, MD, Arno Zaritsky, MD, Bonnie Stojadinovic, MD, Jerry Zimmerman, MD, and Aaron Zuckerberg, MD

\section{Affiliations}

\section{ACKNOWLEDGMENTS}

Dr. Brierley received meeting travel expenses from USCOM Ltd. Dr. Nadel has consulted, received honoraria, and study funding from Eli Lilly. Dr. Shanley has received a research grant from the National Institutes of Health.

Approval Committee - Andrew Argent (South Africa), Anton (Indonesia), Ronaldo Arkader (Sao Paolo, Brazil), Debbie Bills, RN (Pittsburgh, PA), Desmond J. Bohn, MBBS (Toronto, Canada), Booy (London, England), Robert Boxer, MD (Roslyn, NY), George Briassoulis (Crete, Greece), Joe Briely (London, England), Richard Brilli, MD (Cincinnati, OH), Cynthia W. Broner, MD (Columbus, OH), Tim Bunchman (Grand Rapids, MI), Warwick Butt (Melbourne, Australia), Hector Carillo (Mexico City, Mexico), Juan Casado-Flores, MD (Spain), Billy Casey (Dublin, Ireland), Leticia Castillo, MD (Boston, MA), Gary D. Ceneviva, MD (Hershey, PA), Karen Choong (Ontario, Canada), Paolo Cogo (London, England), Andrew T. Costarino, MD (Wilmington, DE), Peter Cross (Toronto, Canada), Heidi J. Dalton, MD (Washington, DC), Alan L. Davis, MD (Summit, NJ), M. den Brinker (Rotterdam, The Netherlands), DeKleign (Rotterdam, NE), Lesley A. Doughty, MD (Providence, RI), Michelle Dragotta, RN (Pittsburgh, PA), Trevor Duke (Melbourne, Australia), Alan W. Duncan (Perth, Australia), J.R. Evans (Philadelphia, PA), N. Evans (Sydney, Australia), Elizabeth A. Farrington, PharmD (Durham, NC), Timothy F. Feltes, MD (Columbus, OH), Kate Felmet (Pittsburgh, PA), Melinda Fiedor (Pittsburgh, PA), Jason Foland (Atlanta, GA), James Fortenberry (Atlanta, GA), Brett P. Giroir, MD (Dallas, TX), Brahm Goldstein, MD (Portland, OR), Bruce Greenwald, MD (New York, NY), Mark Hall, MD (Columbus, OH), Yong Y. Han (Ann Arbor, MI), Steven E. Haun, MD (Sioux City, SD), Gabriel J. Hauser, MD (Washington, DC), Jan Hazelzet, MD (Rotterdam, The Netherlands), Sabrina Heidemann, MD (Detroit, MI), Lyn Hernan, MD (Buffalo, NY), Ronald B. 
Hirschl, MD (Ann Arbor, MI), Steven A. Hollenberg, MD (Chicago, IL), Jorge Irazusta, MD (Boston, MA), Brian Jacobs, MD (Cincinnati, OH), Stephen R. Johnson, MD (Los Angeles, CA), K.F. Joosten (Rotterdam The Netherlands), Robert Kanter, MD (Syracuse, NY), Carol King, MD (Buffalo, NY), Bulent Karapinar (Izmir, Turkey), Erica Kirsch, MD (Dallas, TX), M. Kluckow (Sydney, Australia), Martha Kutko (New York, NY), Jacques LaCroix, MD (Montreal, Canada), Stephen A Lawless, MD (Wilmington, DE), Lauterbach (Poland), Francis LeClerc, MD (Lille, France), Michael Levin (London, England), John Lin (San Antonio, TX), Steven E. Lucking, MD (Hershey, PA), Lucy Lum, MD (Kuala Lampur, Malaysia), Kath Maitland (Kilif, Kenya), Michele Mariscalco, MD (Houston, TX), I. Matok (Hashomer, Israel), Cris Mangia (Sao Paolo, Brazil), F.O. Odetola (Ann Arbor, MI), Jean-Christophe Mercier (Paris, France), Richard B. Mink (Los Angeles, CA), M. Michelle Moss, MD (Little Rock, AR), C. Munter (London, England), A.I. Murdoch (London, England), P.C. Ng (Hong Kong), Ninis (London, England), Daniel A. Notterman, MD (Newark, NJ), William Novotny (Greenville, NC), Claudio Oliveira (Sao Paolo, Brasil), D. Osborn (Sydney, Australia), Kristan M. Outwater, MD (Saginaw, MI), J.F. Padbury (Providence, RI), Hector S. Pabon, MD (Brandon, FL), Margaret M. Parker, MD (Stonybrook, NY), J. Alan Paschall, MD (Takoma, WA), Andy Petros (London, England), Jefferson P. Piva (Porto Alegre, Brazil), Ronald M. Perkin, MD (Greenville, NC), Pollard (London, England), Francois Proulx (Montreal, Canada), J. Ranjit (Chennai, India), E.M. Reynolds (Boston, MA), Gerardo Reyes, MD (Oak Lawn, IL), Gustavo Rios (Vina del Mar, Chile), Hannelore Ringe (Berlin, Germany), Ricardo Ronco, MD (Santiago, Chile), Cathy H. Rosenthal-Dichter, MN, CCRN (Yorktown, IN), James Royall, MD (Oklahoma City, OK), Istvan Seri (Los Angeles, CA), Thomas Shanley (Ann Arbor, MI), Billie L. Short, MD (Washington, DC), Sunit Singhi (Chandigarh, India), Peter Skippen (Vancouver, BC), N.V. Subhedar (Liverpool, England), Rod Tarrago (Minneapolis/St. Paul, MN), Neal Thomas (Hershey, PA), S.M. Tibby (London, England), Joseph Tobias (Columbia, MO), Scott Watson (Pittsburgh, PA), Wills (London, England), Arno Zaritsky (Gainesville, FL), Jerry Zimmerman (Seattle, WA).

\section{REFERENCES}

1. DuPont HL, Spink WW. Infections due to gram negative organisms: An analysis of 860 patients with bacteremia at University of Minnesota Medical Center. 1958-1966. Medicine. 1969; 48:307332. [PubMed: 4897133]

2. Stoll BJ, Holman RC, Shuchat A. Decline in sepsis-associated neonatal and infant deaths 19741994. Pediatrics. 1998; 102:e18. [PubMed: 9685463]

3. Angus DC, Linde Zwirble WT, Liddicker J, et al. Epidemiology of severe sepsis in the U.S.: Analysis of incidence, outcome, and associated costs of care. Crit Care Med. 2001; 29:1303-1310. [PubMed: 11445675]

4. Watson RS, Carcillo JA, Linde-Zwirble WT, et al. The epidemiology of severe sepsis in the United States. Am J Respir Crit Care Med. 2003; 167:695-701. [PubMed: 12433670]

5. Carcillo JA, Fields AI. American College of Critical Care Medicine Task Force Committee Members: Clinical practice parameters for hemodynamic support of pediatric and neonatal patients in septic shock. Crit Care Med. 2002; 30:1365-1378. [PubMed: 12072696]

6. Nhan NT, Phuong CXT, Kneen R, et al. Acute management of dengue shock syndrome: A randomized double-blind comparison of 4 intravenous fluid regimens in the first hour. Clin Infect Dis. 2001; 32:204-212. [PubMed: 11170909]

7. Booy R, Habibi P, Nadel S, et al. Meningococcal Research Group: Reduction in case fatality rate from meningococcal disease associated with improved healthcare delivery. Arch Dis Child. 2001; 85:386-390. [PubMed: 11668100]

8. Kutko MC, Calarco MP, Flaherty MB, et al. Mortality rates in pediatric septic shock with and without multiple organ failure. Pediatr Crit Care Med. 2003; 4:333-337. [PubMed: 12831416]

9. Wills BA, Nguyen MD, Ha TL, et al. Comparison of the three fluid solutions for resuscitation in dengue shock. N Engl J Med. 2005; 353:877-889. [PubMed: 16135832]

10. Maitland K, Pamba A, English M, et al. Randomized trial of volume expansion with albumin or saline in children with severe malaria: Preliminary evidence of albumin benefit. Clin Infect Dis. 2005; 40:538-545. [PubMed: 15712076]

11. Han YY, Carcillo JA, Dragotta MA, et al. Early reversal of pediatric-neonatal septic shock by community physicians is associated with improved outcome. Pediatrics. 2003; 112:793-799. [PubMed: 14523168]

12. Ninis N, Phillips C, Bailey L, et al. The role of healthcare delivery on outcome of meningococcal disease in children: Case-control study of fatal and non-fatal cases. BMJ. 2005; 330:1475. [PubMed: 15976421] 
13. de Oliveira CF, de Oliveira DS, Gottschald AF, et al. ACCM/PALS haemodynamic support guidelines for paediatric septic shock: An outcomes comparison with and without monitoring central venous oxygen saturation. Intensive Care Med. 2008; 34:1065-1075. [PubMed: 18369591]

14. Karapinar B, Lin JC, Carcillo JA. ACCM guidelines use, correct antibiotic therapy, and immune suppressant withdrawal are associated with improved survival in pediatric sepsis, severe sepsis, and septic shock. Crit Care Med. 2004; 32(12 Suppl 3):A161.

15. Maat M, Buysse CM, Emonts M, et al. Improved survival in children with sepsis and purpura: Effects of age, gender, and era. Crit Care. 2007; 11:172. [PubMed: 18001494]

16. Odetola FO, Gebremariam A, Freed GL. Patient and hospital correlates of clinical outcomes and resource utilization in severe pediatric sepsis. Pediatrics. 2007; 119:487-494. [PubMed: 17332201]

17. Practice parameters for hemodynamic support of sepsis in adults with sepsis. Task force of the American College of Critical Care Medicine, Society of Critical Care Medicine. Crit Care Med. 1999; 27:695-697. [PubMed: 10321656]

18. Parker MM, Shelhamer JH, Natanson C, et al. Serial cardiovascular variables in survivors and nonsurvivors of human septic shock: Heart rate as an early predictor of prognosis. Crit Care Med. 1987; 15:923-929. [PubMed: 3652707]

19. Parker MM, Shelhamer JH, Bacharach SL, et al. Profound but reversible myocardial depression in patients with septic shock. Ann Intern Med. 1984; 100:483-490. [PubMed: 6703540]

20. Pollack MM, Fields AI, Ruttimann UE, et al. Sequential cardiopulmonary variables of infants and children in septic shock. Crit Care Med. 1984; 12:554-559. [PubMed: 6734222]

21. Pollack MM, Fields AI, Ruttimann UE. Distributions of cardiopulmonary variables in pediatric survivors and nonsurvivors of septic shock. Crit Care Med. 1985; 13:454-459. [PubMed: 3995997]

22. Carcillo JA, Pollack MM, Ruttimann UE, et al. Sequential physiologic interactions in cardiogenic and septic shock. Crit Care Med. 1989; 17:12-16. [PubMed: 2909315]

23. Monsalve F, Rucabado L, Salvador A, et al. Myocardial depression in septic shock caused by meningococcal infection. Crit Care Med. 1984; 12:1021-1023. [PubMed: 6439470]

24. Mercier JC, Beaufils F, Hartmann JF, et al. Hemodynamic patterns of meningococcal shock in children. Crit Care Med. 1988; 16:27-33. [PubMed: 3338278]

25. Simma B, Fritz MG, Trawoger R, et al. Changes in left ventricular function in shocked newborns. Intensive Care Med. 1997; 23:982-986. [PubMed: 9347371]

26. Walther FJ, Siassi B, Ramadan NA. Cardiac output in newborn infants with transient myocardial dysfunction. J Pediatr. 1985; 107:781-785. [PubMed: 4056980]

27. Ferdman B, Jureidini SB, Mink RB. Severe left ventricular dysfunction and arrhythmias as complication of gram positive sepsis: Rapid recovery in children. Pediatr Cardiol. 1998; 19:482486. [PubMed: 9770579]

28. Feltes TF, Pignatelli R, Kleinert S, et al. Quantitated left ventricular systolic mechanics in children with septic shock utilizing noninvasive wall stress analysis. Crit Care Med. 1994; 22:1647-1659. [PubMed: 7924378]

29. Ceneviva G, Paschall JA, Maffei F, et al. Hemodynamic support in fluid refractory pediatric septic shock. Pediatrics. 1998; 102:e19. [PubMed: 9685464]

30. Hoban LD, Paschal JA, Eckstein J, et al. Awake porcine model of intraperitoneal sepsis and altered oxygen utilization. Circ Shock. 1991; 34:252-262. [PubMed: 1934326]

31. Green EM, Adams HR. New perspectives in circulatory shock: Pathophysiologic mediators of the mammalian response to endotoxemia and sepsis. J Am Vet Med Assoc. 1992; 200:1834-1841. [PubMed: 1639688]

32. McDonough KH, Brumfield BA, Lang CH. In vitro myocardial performance after lethal and nonlethal doses of endotoxin. Am J Physiol. 1986; 250:H240-H246. [PubMed: 3946624]

33. Natanson C, Fink MP, Ballantyne HK, et al. Gram-negative bacteremia produces both severe systolic and diastolic cardiac dysfunction in a canine model that simulates human septic shock. $\mathrm{J}$ Clin Invest. 1986; 78:259-270. [PubMed: 3722379] 
34. Brierly J, Thiruchelvan T, Peters MJ. Hemodynamics of early pediatric fluid resistant septic shock using non-invasive cardiac output (USCOM) distinct profiles of CVC infection and community acquired sepsis. Crit Care Med. 2006; 33:171-I.

35. Dobkin ED, Lobe TE, Bhatia J, et al. The study of fecal E. coli peritonitis-induced septic shock in a neonatal pig model. Circ Shock. 1985; 16:325-336. [PubMed: 3915235]

36. Sosa G, Milstein JM, Bennett SH. E. coli endotoxin depresses left ventricular contractility in neonatal lambs. Pediatr Res. 1994; 35:62-67. [PubMed: 8134201]

37. Peevy KJ, Chartrand SA, Wiseman HJ, et al. Myocardial dysfunction in group B streptococcal shock. Pediatr Res. 1994; 19:511-513. [PubMed: 3892470]

38. Meadow WL, Meus PJ. Unsuspected mesenteric hypoperfusion despite apparent hemodynamic recovery in the early phase of septic shock in piglets. Circ Shock. 1985; 15:123-129. [PubMed: 3884175]

39. Meadow WL, Meus PJ. Early and late hemodynamic consequences of group B beta streptococcal sepsis in piglets: Effects on systemic, pulmonary, and mesenteric circulations. Circ Shock. 1986; 19:347-356. [PubMed: 3527468]

40. Gill AB, Wendling AM. Echocardiographic assessment of cardiac function in shocked very low birthweight infants. Arch Dis Child. 1993; 68(1 Spec No):17-21. [PubMed: 8439190]

41. Kluckow M. Low systemic blood flow and pathophysiology of the preterm transitional circulation. Early Hum Dev. 2005; 81:429-437. [PubMed: 15935920]

42. Munro MJ, Walker AM, Barfield CP. Hypotensive extremely low birth weight infants have reduced cerebral blood flow. Pediatrics. 2004; 114:1591-1596. [PubMed: 15574619]

43. Jayasinghe D, Gill AB, Levene MI. CBF reactivity in hypotensive and normotensive preterm infants. Pediatr Res. 2003; 54:848-853. [PubMed: 12904589]

44. Vavilala MS, Lam AM. CBF reactivity to changes in MAP (cerebral autoregulation) or $\mathrm{CO}_{2}\left(\mathrm{CO}_{2}\right.$ reactivity) is lost in hypotensive, ventilated, preterm infants. Pediatr Res. 2004; 55:898-899. [PubMed: 15100394]

45. Al-Aweel I, Pursley DM, Rubin LP, et al. Variations in prevalence of hypotension, hypertension, and vasopressor use in NICUs. J Perinat. 2001; 21:272-278.

46. Martens SE, Rijken M, Stoelhorst GN, et al. Is hypotension a risk factor for neurological morbidity at term in very preterm infants? Early Hum Dev. 2003; 75:79-89. [PubMed: 14652161]

47. Subhedar NV. Treatment of hypotension in newborns. Semin Neonatol. 2003; 8:413-423. [PubMed: 15001113]

48. Seri I, Noori S. Diagnosis and treatment of neonatal hypotension outside the transitional period. Early Hum Dev. 2005; 81:405-411. [PubMed: 15882935]

49. Noori S, Seri I. Pathophysiology of newborn hypotension outside the transitional period. Early Hum Dev. 2005; 81:399-404. [PubMed: 15878243]

50. Evans JR, Lou Short B, Van Meurs K, Cheryl Sachs H. Cardiovascular support of preterm infants. Clin Ther. 2006; 28:1366-1384. [PubMed: 17062310]

51. Evans N. Which inotrope for which baby? Arch Dis Child Fetal Neonatal Ed. 2006; 91:F213F220. [PubMed: 16632650]

52. Osborn DA. Diagnosis and treatment of preterm transitional circulatory compromise. Early Hum Dev. 2005; 81:413-422. [PubMed: 15935918]

53. Evans N. Management of hypotension and circulatory assessment on NICU. Early Hum Dev. 2005; 81:397-398. [PubMed: 15869848]

54. Seri I. Inotrope, lusitrope, and pressor use in neonates. J Perinatol. 2005; 25(Suppl 2):528-530.

55. Schonberger W, Grimm W, Gemp W, et al. Transient hypothyroidism associated with prematurity, sepsis, and respiratory distress. Eur J Pediatr. 1979; 132:85-92. [PubMed: 499263]

56. Roberton NR, Smith MA. Early neonatal hypocalcemia. Arch Dis Child. 1975; 50:604-609. [PubMed: 1106332]

57. Efird MM, Heerens AT, Gordon PV, et al. A randomized controlled trial of prophylactic hydrocortisone supplementation for the prevention of hypotension in extremely low birth weight infants. J Perinatol. 2005; 25:119-124. [PubMed: 15329742] 
58. Ng PC, Lee CH, Bnur FL. A double blind, randomized controlled study of a stress dose of hydrocortisone for rescue treatment of refractory hypotension in preterm infants. Pediatrics. 2006; 117:367-375. [PubMed: 16452355]

59. Fernandez E, Schrader R, Wattenberg K. Prevalence of low cortisol values in term and near term infants with vasopressor resistant hypotension. J Perinatol. 2005; 25:114-118. [PubMed: 15526013]

60. Noori S, Siassi B, Durand M, et al. Cardiovascular effects of low dose dexamethasone in very low birth weight neonates with refractory hypotension. Biol Neonate. 2006; 89:82-87. [PubMed: 16158007]

61. Lauterbach R, Pawlik D, Kowalczyk D, et al. The effect of the immunomodulatory agent, pentoxyfilline in the treatment of sepsis in prematurely delivered infants; placebo controlled, double blinded trial. Crit Care Med. 1999; 27:807-814. [PubMed: 10321674]

62. Zimmerman JJ. Appraising the potential of pentoxyfilline in septic premies. Crit Care Med. 1999; 27:695-697. [PubMed: 10321656]

63. Haque K, Mohan P. Pentoxifylline for neonatal sepsis. Cochrane Database Syst Rev. 2003:CD004205. [PubMed: 14584009]

64. Fenton KE, Sable CA, Bell MJ, et al. Increases in serum levels of troponin I are associated with cardiac dysfunction and disease severity in pediatric patients with septic shock. Pediatr Crit Care Med. 2004; 5:533-536. [PubMed: 15530188]

65. Briassoulis G, Narlioglou, Zavras N, et al. Myocardial injury in meningococcus-induced purpura fulminans in children. Intensive Care Med. 2001; 27:1073-1082. [PubMed: 11497141]

66. Thiru Y, Pathan N, Bignall S, et al. A myocardial cytotoxic process is involved in the cardiac dysfunction of meningococcal septic shock. Crit Care Med. 2000; 28:2979-2983. [PubMed: 10966282]

67. Pollack MM, Ruttiman UE, Getson PR, et al. Pediatric risk of mortality (PRISM) score. Crit Care Med. 1988; 16:1110-1116. [PubMed: 3048900]

68. Carcillo JA, Kuch BA, et al. Early shock reversal is associated with reduced childhood neurologic morbidity and mortality. Pediatrics. in press.

69. Redl-Wenzl EM, Armbruster C, Edelman G, et al. The effects of norepinephrine on hemodynamics and renal function in severe septic shock. Intensive Care Med. 1993; 19:151-154. [PubMed: 8315122]

70. LeDoux D, Astiz ME, Carpati CM, et al. Effects of perfusion pressure on tissue perfusion in septic shock. Crit Care Med. 2000; 28:2729-2732. [PubMed: 10966242]

71. Greenhalgh DG, Warden GD. The importance of intra-abdominal pressure measurements in burned children. J Trauma. 1994; 36:685-690. [PubMed: 8189471]

72. Evans N, Osborn D, Kluckow M. Preterm circulatory support is more complex than just blood pressure. Pediatrics. 2005; 115:1114-1115. [PubMed: 15805413]

73. Osborn DA, Evan N, Kluckow M. Clinical detection of low upper body blood flow in very premature infants using blood pressure, capillary refill time, and central- Peripheral temperature difference. Arch Dis Child Fetal Neonatal Ed. 2004; 69:F168-F173. [PubMed: 14977905]

74. Hunt RW, Evans N, Rieger I, et al. Low superior vena cava flow and neurodevelopment at 3 years in very pre term infants. J Pediatr. 2004; 145:588-592. [PubMed: 15520755]

75. Evans N, Kluckow M, Simmons M, et al. Which to measure, systemic or organ blood flow? Middle cerebral artery and superior vena cava blood flow in very preterm infants. Arch Dis Child Fetal Neonatal Ed. 2002; 87:F181-F184. [PubMed: 12390987]

76. Osborn DA, Evans N, Kluckow M. Hemodynamic and antecedent risk factors of early and late periventricular/intraventricular hemorrhage in premature infants. Pediatrics. 2003; $112(1 \mathrm{Pt} 1): 33$ 39. [PubMed: 12837865]

77. Osborn DA, Evans N, Kluckow M. Effect of targeted indomethacin on the ductus arteriosus and blood flow to the upper body and brain in the preterm infant. Arch Dis Child Fetal Neonatal Ed. 2003; 88:F477-F482. [PubMed: 14602694]

78. Osborn D, Evans N, Kluckow M. Randomized trial of dobutamine versus dopamine in preterm infants with low systemic blood flow. J Pediatr. 2002; 140:183-191. [PubMed: 11865269] 
79. Evans N, Osborn D, Kluckow M. Mechanism of blood pressure increase induced by dopamine in hypotensive preterm neonates. Arch Dis Child Fetal Neonatal Ed. 2000; 83:F75-F76. [PubMed: 10917724]

80. Kluckow M. Low systemic blood flow in the preterm infant. Semin Neonatol. 2001; 6:75-84. [PubMed: 11162287]

81. Kluckow M, Evans N. Ductal shunting, high pulmonary blood flow, and pulmonary hemorrhage. J Pediatr. 2000; 137:68-72. [PubMed: 10891824]

82. Kluckow M, Evans N. Low superior vena cava flow and intraventricular haemorrhage in preterm infants. Arch Dis Child Fetal Neonatal Ed. 2000; 82:F188-F194. [PubMed: 10794784]

83. Parr GV, Blackstone EH, Kirklin JW. Cardiac performance and mortality early after intracardiac surgery in infants and young children. Circulation. 1975; 51:867-874. [PubMed: 235375]

84. Rivers E, Nguyen B, Havstad S, et al. Early goal-directed therapy in the treatment of severe sepsis and septic shock. N Engl J Med. 2001; 346:1368-1377. [PubMed: 11794169]

85. Kanter RK, Zimmerman JJ, Strauss RH, et al. Pediatric emergency intravenous access. Evaluation of a protocol. Am J Dis Child. 1986; 140:132-134. [PubMed: 3946322]

86. Idris AH, Melker RS. High flow sheaths for pediatric fluid resuscitation: A comparison of flow rates with standard pediatric catheters. Pediatr Emerg Care. 1992; 8:119-122. [PubMed: 1614899]

87. Ngo NT, Cao XT, Kneen R, et al. Acute management of dengue shock syndrome: A randomized double-blind comparison of 4 intravenous fluid regimens in the first hour. Clin Infect Dis. 2001; 32:204-213. [PubMed: 11170909]

88. Dung NM, Day NP, Tam DT, et al. Fluid replacement in dengue shock syndrome: A randomized double blind comparison of four intravenous fluid regimens. Clin Infect Dis. 1999; 29:787-794. [PubMed: 10589889]

89. Finfer S, Bellomo R, Boyce N, et al. SAFE Study Investigators: A comparison of albumin and saline for fluid resuscitation in the intensive care unit. N Engl J Med. 2004; 350:2247-2256. [PubMed: 15163774]

90. Upadhyay M, Singhi S, Murlidharan J, et al. Randomized evaluation of fluid resuscitation with crystalloid (saline) and colloid (polymer from degraded gelatin in saline) in pediatric septic shock. Indian Pediatr. 2005; 42:223-231. [PubMed: 15817970]

91. Carcillo JA, Davis AI, Zaritsky A. Role of early fluid resuscitation in pediatric septic shock. JAMA. 1991; 266:1242-1245. [PubMed: 1870250]

92. Stoner MJ, Goodman DG, Cohen DM, et al. Rapid fluid resuscitation in pediatrics; testing the ACCM guidelines. Crit Care Med. 2005; 33:A68.

93. Ranjit S, Kissoon N, Jayakumar I. Aggressive management of dengue shock syndrome may decrease mortality rate: A suggested protocol. Pediatr Crit Care Med. 2005; 6:412-419. [PubMed: 15982427]

94. Foland FA, Fortenberry JD, Warshaw BL, et al. Fluid overload before continuous hemofiltration and survival in critically ill children; a retrospective analysis. Crit Care Med. 2004; 32:1771-1776. [PubMed: 15286557]

95. Lucking SE, Williams TM, Chaten FC. Dependence of oxygen consumption on oxygen delivery in children with hyperdynamic septic shock and low oxygen extraction. Crit Care Med. 1990; 18:1316-1319. [PubMed: 2245603]

96. Mink RB, Pollack MM. Effect of blood transfusion on oxygen consumption in pediatric septic shock. Crit Care Med. 1990; 18:1087-1091. [PubMed: 2209035]

97. Carrol CG, Snyder JV. Hyperdynamic severe intravascular sepsis depends on fluid administration in cynomolgous monkey. Am J Physiol. 1982; 243:R131-R141. [PubMed: 7046476]

98. Lee PK, Deringer JR, Kreiswirth BN, et al. Fluid replacement protection of rabbits challenged subcutaneous with toxic shock syndrome toxins. Infect Immun. 1991; 59:879-884. [PubMed: 1997438]

99. Ottoson J, Dawidson I, Brandberg A, et al. Cardiac output and organ blood flow in experimental septic shock and treatment with antibiotics, corticosteroids, and fluid infusion. Circ Shock. 1991; 35:14-24. [PubMed: 1742857]

100. Hoban LD, Paschall JA, Eckstein J, et al. Awake porcine model of intraperitoneal sepsis and altered oxygen utilization. Circ Shock. 1991; 34:252-262. [PubMed: 1934326] 
101. Wilson MA, Choe MC, Spain DA. Fluid resuscitation attenuates early cytokine mRNA expression after peritonitis. J Trauma. 1996; 41:622-627. [PubMed: 8858019]

102. Boldt J, Muller M, Heesen M. Influence of different volume therapies and pentoxifylline infusion on circulating adhesion molecules in critically ill patients. Crit Care Med. 1998; 24:385-391. [PubMed: 8625624]

103. Zadrobilek E, Hackl W, Sporn P, et al. Effect of large volume replacement with balanced electrolyte solutions on extravascular lung water in surgical patients with sepsis syndrome. Intensive Care Med. 1989; 15:505-510. [PubMed: 2607037]

104. Powell KR, Sugarman LI, Eskenazi AE, et al. Normalization of plasma arginine vasopressin concentrations when children with meningitis are given maintenance plus replacement fluid therapy. J Pediatr. 1990; 117:515-522. [PubMed: 2213375]

105. Pladys P, Wodey E, Betremieux P. Effects of volume expansion on cardiac output in the preterm infant. Acta Paediatr. 1997; 86:1241-1245. [PubMed: 9401521]

106. Lambert HJ, Baylis PH, Coulthard MG. Central-peripheral temperature difference, blood pressure, and arginine vasopressin in preterm neonates undergoing volume expansion. Arch Dis Child Fetal Neonatal Ed. 1998; 78:F43-F45. [PubMed: 9536840]

107. Bressack MA, Morton NS, Hortop J. Group B streptococcal sepsis on the piglet: Effects of fluid therapy on venous return, organ edema, and organ blood flow. Circ Res. 1987; 61:659-669. [PubMed: 3311447]

108. Pollard AJ, Britto J, Nadel S, et al. Emergency management of meningococcal disease. Arch Dis Child. 1999; 80:290-296. [PubMed: 10325716]

109. Cochrane Injuries Group. Human albumin administration in critically ill patients: Systematic review of randomized controlled trials. BMJ. 1998; 317:235-240. [PubMed: 9677209]

110. Boldt J, Heesen M, Welters I. Does the type of volume therapy influence endothelial-related coagulation in the critically ill? Br J Anaesth. 1995; 75:740-746. [PubMed: 8672323]

111. Oca MJ, Nelson M, Donn SM. Randomized trial of normal saline versus 5\% albumin for the treatment of neonatal hypotension. J Perinatol. 2003; 23:473-476. [PubMed: 13679934]

112. Pamba A, Maitland K. Capillary refill: prognostic value in Kenyan children. Arch Dis Child. 2004; 89:950-955. [PubMed: 15383440]

113. Maitland K, Pamba A, English M, et al. Pre-transfusion management of children with severe malarial anemia: A randomized controlled trial of intravascular expansion. Br J Haematol. 2005; 128:393-400. [PubMed: 15667544]

114. Liet JM, Kuster A, Denizot S, et al. Effects of hydroxyethyl starch on cardiac output in hypotensive neonates: A comparison with isotonic saline and 5\% albumin. Acta Paediatr. 2006; 95:555-560. [PubMed: 16825135]

115. Cam BV, Tuan DT, Fonsmark L, et al. Randomized comparison of oxygen mask treatment vs nasal continuous positive airway pressure in dengue shock syndrome with acute respiratory failure. J Trop Pediatr. 2002; 48:335-339. [PubMed: 12521274]

116. Yamamoto, LG. Rapid sequence intubation. In: Ludwig, S.; Fleisher, GR., editors. Textbook of Pediatric Emergency Care. Philadelphia, PA: Lippincott, Wilkins and Williams; 2000.

117. Van der, Linde P.; Gilbart, E.; Engelman, E., et al. Comparison of halothane, isoflurane, alfentanil, and ketamine in experimental septic shock. Anesth Analg. 1990; 70:608-617. [PubMed: 2188526]

118. Neder Meyer T, Lazaro Da Silva A. Ketamine reduces mortality of severely burnt rats, when compared to midazolam plus fentanyl. Burns. 2004; 30:425-430. [PubMed: 15225906]

119. Song XM, Wang YL, Zhou Q, et al. Protective effect of ketamine against septic shock in rats. Zhongguo Wei Zhuong Bing Ji Jiu Yi Xue. 2004; 16:348-351.

120. Koga K, Ogata M, Takenaka I, et al. Ketamine suppresses tumor necrosis factor alpha activity and mortality in carrageenan-sensitized endotoxin shock model. Circ Shock. 1994; 44:160-168. [PubMed: 7600640]

121. Taniguchi T, Takemoto Y, Kanakura H, et al. The dose related effects of ketamine on mortality and cytokine response to endotoxin induced shock in rats. Anesth Analg. 2003; 97:1769-1772. [PubMed: 14633557] 
122. Taniguchi T, Kanakura H, Takemoto Y, et al. The anti-inflammatory effects of ketamine in endotoxemic rats during moderate and mild hypothermia. Anesth Analg. 2004; 98:1114-1120. [PubMed: 15041609]

123. Taniguchi T, Shibata K, Yamamoto K. Ketamine inhibits endotoxin induced shock in rats. Anesthesiology. 2001; 95:928-932. [PubMed: 11605934]

124. Yli-Hankala A, Kirveta M, Randell T, et al. Ketamine anaesthesia in a patient with septic shock. Acta Anaesthesiol Scand. 1992; 36:483-485. [PubMed: 1632173]

125. Modig J. Positive effects of ketamine v. metomidate anesthesia on cardiovascular function, oxygen delivery and survival. Studies with a porcine endotoxin model. Acta Chir Scand. 1987; 153:7-13. [PubMed: 2883794]

126. Tobias J, Martin LD, Wetzel RC. Ketamine by continuous infusion for sedation in the pediatric intensive care unit. Crit Care Med. 1990; 18:819-821. [PubMed: 2379394]

127. Bloomfield R, Noble DW. Etomidate and fatal outcome-Even after a single dose may be detrimental for some patients. Br J Anaesth. 2006; 97:116-117. [PubMed: 16769703]

128. den, Brinker M.; Joosten, KF.; Liem, O., et al. Adrenal insufficiency in meningococcal sepsis: Bioavailable cortisol levels and impact of interleukin-6 levels and intubation with etomidate on adrenal function and mortality. J Clin Endocrinol Metab. 2005; 90:5110-5117. [PubMed: 15985474]

129. Jackson WL Jr. Should we use etomidate as an induction agent for endotracheal intubation with septic shock? A critical appraisal. Chest. 2005; 127:1031-1038. [PubMed: 15764790]

130. Annane D. ICU physicians should abandon the use of etomidate! Intensive Care Med. 2005; 31:325-326. [PubMed: 15750800]

131. Morris C, Mc Allister C. Etomidate for emergency anesthesia; mad, bad and dangerous to know? Anaesthesia. 2005; 60:737-740. [PubMed: 16029220]

132. Fernandez EG, Green TP, Sweenet M. Low inferior vena caval catheters for hemodynamic and pulmonary function monitoring in pediatric critical care patients. Pediatr Crit Care Med. 2004; 5:14-18. [PubMed: 14697103]

133. Reynolds EM, Ryan DP, Sheridan RL, et al. Left ventricular failure complicating severe pediatric burn injury. J Pediatr Surg. 1995; 30:264-269. [PubMed: 7738749]

134. Zaritsky A. Curr Concepts Ped Emerg Care. 1998

135. Morrow WR, Murphy DJ Jr, Fisher DJ, et al. Continuous wave Doppler cardiac output: Use in pediatric patients receiving inotropic support. Pediatr Cardiol. 1988; 9:131-136. [PubMed: 3141908]

136. Duke T, Butt W, South M. Predictors of mortality and multiple organ failure in children with sepsis. Intensive Care Med. 1997; 23:684-692. [PubMed: 9255650]

137. Gueugniaud PY, Muchada R, Moussa M, et al. Continuous esophageal aortic blood flow echoDoppler measurement during general anesthesia in infants. Can J Anaesth. 1997; 44:745-750. [PubMed: 9232306]

138. Tibby SM, Hatherill M, Marsh MJ, et al. Clinical validation of cardiac output measurement using femoral artery thermodilution with direct Fick in ventilated children and adults. Intensive Care Med. 1997; 23:987-991. [PubMed: 9347372]

139. McLuckie A, Murdoch IA, Marsh MJ, et al. Comparison of pulmonary artery and thermodilution cardiac indices in pediatric intensive care patients. Acta Paediatr. 1996; 85:336-338. [PubMed: 8695992]

140. Bay-Hansen R, Elfving B, Greisen G. Use of near infrared spectroscopy for estimation of peripheral venous saturation in newborns: Comparison with co-oximetry of central venous blood. Biol Neonate. 2002; 82:1-8. [PubMed: 12119534]

141. Cecchetti C, Stoppa F, Vanacore N, et al. Monitoring of intrathoracic volemia and cardiac output in critically ill children. Minerva Anestesiol. 2003; 69:907-918. [PubMed: 14743122]

142. Courand A, Marshall J, Chang Y, et al. Clinical applications of wall stress analysis in the pediatric intensive care unit. Crit Care Med. 2001; 29:526-533. [PubMed: 11373415]

143. Cua CL, Hoffman TM, Taeed R, et al. Cerebral saturations trend with mixed venous saturations in patients undergoing extracorporeal life support. Perfusion. 2004; 19:171-176. [PubMed: 15298425] 
144. Mahajan A, Shabanie A, Turner J, et al. Pulse contour analysis for cardiac output monitoring in cardiac surgery for congenital heart disease. Anesth Analg. 2003; 97:1283-1288. [PubMed: 14570638]

145. Martin M, Brown C, Bayard D, et al. Continuous noninvasive monitoring of cardiac performance and tissue perfusion in pediatric trauma patients. J Pediatr Surg. 2005; 40:1957-1963. [PubMed: 16338328]

146. Mohan UR, Britto J, Habibi P, et al. Noninvasive measurement of cardiac output in critically ill children. Pediatr Cardiol. 2002; 32:58-61. [PubMed: 11922510]

147. Nicklin SE, Hassan IA, Wickramasinghe YA, et al. The light shines but not that brightly? The current status of perinatal near infrared spectroscopy. Arch Dis Child Fetal Neonatal Ed. 2003; 88:F263-F268. [PubMed: 12819155]

148. Pauli C, Fakle U, Genz T, et al. Cardiac output determination in children: equivalence of the transpulmonary thermodilution method to the direct Fick principle. Intensive Care Med. 2002; 28:947-952. [PubMed: 12122535]

149. Sloth E, Pedersen J, Olsen KH, et al. Transesophageal echocardiographic monitoring during pediatric cardiac surgery: obtainable information and feasibility in 532 children. Paediatr Anaesth. 2001; 11:657-662. [PubMed: 11696140]

150. Tibby SM, Hatherill M, Durward A, et al. Are tranesophageal Doppler parameters a reliable guide to paediatric hemodynamic status and fluid management? Intensive Care Med. 2001; 27:201205. [PubMed: 11280635]

151. Tibby SM, Murdoch IA. Monitoring cardiac function in intensive care. Arch Dis Child. 2003; 88:46-52. [PubMed: 12495962]

152. Torgay A, Pirat A, Akpek E, et al. Pulse contour cardiac output system use in pediatric orthotopic liver transplantation: Preliminary report of nine patients. Transplant Proc. 2005; 37:3168-3170. [PubMed: 16213339]

153. Kim KK, Frankel LR. The need for inotropic support in a subgroup of infants with severe life threatening respiratory syncytial viral infection. J Investig Med. 1997; 45:469-473.

154. Jardin, Eveleigh MC, Gurdjian F, et al. Venous admixture in human septic shock: Comparative effects on blood volume expansion, dopamine infusion and isoproterenol infusion on mismatch of ventilation and pulmonary blood flow in peritonitis. Circulation. 1979; 60:155-159. [PubMed: 445718]

155. Harada K, Tamura M, Ito T, et al. Effects of low-dose dobutamine on left ventricular diastolic filling in children. Pediatr Cardiol. 1996; 17:220-225. [PubMed: 8662043]

156. Stopfkuchen H, Schranz D, Huth R, et al. Effects of dobutamine on left ventricular performance in newborns as determined by systolic time intervals. Eur J Pediatr. 1987; 146:135-139. [PubMed: 3569349]

157. Stopfkuchen H, Queisser-Luft A, Vogel K. Cardiovascular responses to dobutamine determined by systolic time intervals in preterm infants. Crit Care Med. 1990; 18:722-724. [PubMed: 2364711]

158. Habib DM, Padbury JF, Anas NG, et al. Dobutamine pharmacokinetics and pharmacodynamics in pediatric intensive care patients. Crit Care Med. 1992; 20:601-608. [PubMed: 1572184]

159. Berg RA, Donnerstein RL, Padbury JF. Dobutamine infusions in stable, critically ill children: Pharmacokinetics and hemodynamic actions. Crit Care Med. 1993; 21:678-686. [PubMed: 8482088]

160. Martinez AM, Padbury JF, Thio S. Dobutamine pharmacokinetics and pharmacodynamics and cardiovascular responses in critically ill neonates. Pediatrics. 1992; 89:47-51. [PubMed: 1728020]

161. Perkin RM, Levin DL, Webb R, et al. Dobutamine: A hemodynamic evaluation in children with shock. J Pediatr. 1982; 100:977-983. [PubMed: 7086606]

162. Goto M, Griffin A. Adjuvant effects of beta-adrenergic drugs on indomethacin treatment of newborn canine endotoxic shock. J Pediatr Surg. 1991; 26:1156-1160. [PubMed: 1779323]

163. Subhedar NV, Shaw NJ. Dopamine versus dobutamine for hypotensive preterm infants. Cochrane Database Syst Rev. 2003:CD001242. [PubMed: 12917901] 
164. Clark SJ, Yoxall CW, Subhedar NV. Right ventricular performance in hypotenisve preterm neonates treated with dopamine. Pediatr Cardiol. 2002; 23:167-170. [PubMed: 11889528]

165. Lopez SL, Leighton JO, Walther FJ. Supranormal cardiac output in the dopamineand dobutamine-dependent preterm infant. Pediatr Cardiol. 1997; 18:292-296. [PubMed: 9175527]

166. Beale RJ, Hollenberg SM, Vincent JL, et al. Vasopressor and inotropic support in septic shock: An evidence based review. Crit Care Med. 2004; 32(Suppl 11):S455-S465. [PubMed: 15542956]

167. Klinzing S, Simon M, Reinhart K, et al. High-dose vasopressin is not superior to norepinephrine in septic shock. Crit Care Med. 2003; 31:2646-2650. [PubMed: 14605537]

168. Morimatsu H, Singh K, Uchino S, et al. Early and exclusive use of norepinephrine in septic shock. Resuscitation. 2004; 62:249-254. [PubMed: 15294412]

169. Lopez A, Lorente JA, Steingrub J, et al. Multiple-center, randomized, placebo-controlled, doubleblind study of the nitric oxide synthase inhibitor 546C88: Effect on survival in patients with septic shock. Crit Care Med. 2004; 32:21-30. [PubMed: 14707556]

170. Albanese J, Leone M, Delmas A, et al. Terlipressin or norepinephrine in hyperdynamic septic shock: A prospective, randomized study. Crit Care Med. 2005; 33:1897-1902. [PubMed: 16148457]

171. Bollaert PE, Bauer P, Audibert G, et al. Effects of epinephrine on hemodynamics and oxygen metabolism in dopamineresistant septic shock. Chest. 1990; 98:949-953. [PubMed: 2209154]

172. Heckmann M, Trotter A, Pohlandt F, et al. Epinephrine treatment of hypotension in very low birthweight infanst. Acta Paediatr. 2002; 91:566-570. [PubMed: 12113327]

173. Pellicer A, Valverde E, Elorza MD, et al. Cardiovascular support for low birth weight infants and cerebral hemodynamics: A randomized, blinded, clinical trial. Pediatrics. 2005; 115:1501-1512. [PubMed: 15930210]

174. Valverde E, Pellicer A, Madero R, et al. Dopamine versus epinephrine for cardiovascular support in low birth weight infants: Analysis of systemic effects and neonatal outcomes. Pediatrics. 2006; 117:e1213-e1222. [PubMed: 16717120]

175. Meier-Hellman A, Reinhart K, Bredle DC, et al. Epinephrine impairs splanchnic perfusion in septic shock. Crit Care Med. 1997; 25:399-404. [PubMed: 9118653]

176. The International Liaison Committee on Resuscitation (ILCOR) consensus on science with treatment recommendations for pediatric, neonatal patients: Pediatric basic and advanced life support. Pediatrics. 2006; 117:e955-e977. [PubMed: 16618790]

177. Keeley SR, Bohn DJ. The use of inotropic and afterload-reducing agents in neonates. Clin Perinatol. 1988; 15:467-489. [PubMed: 3066549]

178. Butt W, Bohn D, Whyte H. Clinical experience with systemic vasodilator therapy in the newborn infant. Aust Pediatr J. 1986; 22:117-120.

179. Benitz WE, Rhine WD, Van Meurs KP, et al. Nitrosovasodilator therapy for severe respiratory distress syndrome. J Perinatol. 1996; 16:443-448. [PubMed: 8979182]

180. Wong AF, McCulloch LM, Sola A. Treatment of peripheral tissue ischemia with topical nitroglycerin ointment in neonates. J Pediatr. 1992; 121:980-983. [PubMed: 1447671]

181. Bailey JM, Miller BE, Kanter KR, et al. A comparison of the hemodynamic effects of amrinone and sodium nitroprusside in infants after cardiac surgery. Anesth Analg. 1997; 84:294-298. [PubMed: 9024017]

182. Laitinen P, Happonen JM, Sairanae H, et al. Amrinone vs dopamine-nitroglycerin after reconstructive surgery for complete atrio-ventricular septal defect. J Cardiothorac Vasc Anesth. 1997; 11:870-874. [PubMed: 9412887]

183. Spronk PE, Ince C, Gardien MJ, et al. Nitroglycerin in septic shock after intravascular volume resuscitation. Lancet. 2002; 360:1395-1396. [PubMed: 12423989]

184. Heyderman RS, Klein NJ, Shennan GI, et al. Deficiency of prostacyclin production in meningococcal shock. Arch Dis Child. 1991; 66:1296-1299. [PubMed: 1755641]

185. Lauterbach R, Zembala M. Pentoxifylline reduces plasma tumor necrosis factor-alpha concentration in premature infants with sepsis. Eur J Pediatr. 1996; 155:404-409. [PubMed: 8741040] 
186. Kawczynski P, Piotrowski A. Circulatory and diuretic effects of dopexamine infusion in lowbirth-weight infants with respiratory failure. Intensive Care Med. 1996; 22:65-70. [PubMed: 8857441]

187. Habre W, Beghetti M, Roduit C, et al. Hemodynamic and renal effects of dopexamine after cardiac surgery in children. Anaesth Intensive Care. 1996; 24:435-439. [PubMed: 8862639]

188. Moffet BS, Orellana R. Use of fenoldopam to increase urine output in a patient with renal insufficiency secondary to septic shock: A case report. Pediatr Crit Care Med. 2006; 7:600-602. [PubMed: 17006385]

189. Morelli A, Rocco M, Conti G, et al. Effects of short term fenoldopam infusion on gastric mucosal blood flow in septic shock. Anesthesiology. 2004; 101:576-582. [PubMed: 15329581]

190. Barton P, Garcia J, Kouatli A, et al. Hemodynamic effects of i.v. milrinone lactate in pediatric patients with septic shock. A prospective, double-blinded, randomized, placebo-controlled, interventional study. Chest. 1996; 109:1302-1312. [PubMed: 8625683]

191. Lindsay CA, Barton P, Lawless S, et al. Pharmacokinetics and pharmacodynamics of milrinone lactate in pediatric patients with septic shock. J Pediatr. 1998; 132:329-334. [PubMed: 9506650]

192. Paradsis M, Evans N, Kluckow M, et al. Pilot study of milrinone for low sysyemic blood flow in very preterm infants. J Pediatr. 2006; 148:306-313. [PubMed: 16615956]

193. Paradsis M, Jiang X, Mclachlan AJ, et al. Population pharmacokinetics and dosing regimen design of milrinone in preterm infants. Arch Dis Child Fetal Neonatal Ed. 2007; 92:F204-F209. [PubMed: 16690639]

194. Irazusta JE, Pretzlaff RK, Rowin ME. Amrinone in pediatric refractory shock: An open label pharmacodynamic study. Pediatr Crit Care Med. 2001; 2:24-28. [PubMed: 12797884]

195. Sorenson GK, Ramamoorthy C, Lynn AM, et al. Hemodynamic effects of amrinone in children after Fontan surgery. Anesth Analg. 1996; 82:241-246. [PubMed: 8561320]

196. Chang AC, Atz AM, Wernovsky G, et al. Milrinone: Systemic and pulmonary hemodynamics effects in neonates after cardiac surgery. Crit Care Med. 1995; 23:1907-1914. [PubMed: 7587268]

197. Matejovic M, Krouzecky A, Radej J, et al. Successful reversal of resistant hypodynamic septic shock with levosimendan. Acta Anaesthesiol Scand. 2005; 49:127-128. [PubMed: 15676005]

198. Noto A, Giacomini M, Palandi A, et al. Levosimendan in septic cardiac failure. Intensive Care Med. 2005; 31:164-165. [PubMed: 15580334]

199. Oldner A, Konrad D, Weitzberg E, et al. Effects of levosimendan, a novel inotropic calcium sensitizing drug in experimental septic shock. Crit Care Med. 2001; 29:2185-2193. [PubMed: 11700420]

200. Morelli A, Teboul JL, Maggiore SM, et al. Effects of levosimendan on right ventricular afterload in patients with acute respiratory distress syndrome: A pilot study. Crit Care Med. 2006; 34:2287-2293. [PubMed: 16791109]

201. Muller K, Peters A, Zeus T, et al. Therapy of acute decompensated heart failure with levosimendan. Med Klin. 2006; (101Suppl 1):119-122.

202. Namachivayam P, Crossland DS, Butt WW, et al. Early experience with Levosimendan in children with ventricular dysfunction. Pediatr Crit Care Med. 2006; 7:445-448. [PubMed: 16885788]

203. Ringe HI, Varnholt V, Gaedicke G. Cardiac rescue with enoximone in volume and catecholamine refractory septic shock. Pediatr Crit Care Med. 2003; 4:471-475. [PubMed: 14525645]

204. Kern H, Schroder T, Kaulfuss M, et al. Enoximone in contrast to dobutamine improves hepatosplanchnic function in fluid optimized septic shock patients. Crit Care Med. 2001; 29:1519-1525. [PubMed: 11505119]

205. Hoang P, Fosse JP, Fournier JL, et al. Enoximone-noradrenaline combination in septic shock. Presse Med. 1991; 20:1785. [PubMed: 1836604]

206. Sakr Y, Reinhart K, Vincent JL, et al. Does dopamine administration in shock influence outcome? Results of the Sepsis Occurrence in Acutely Ill Patients study. Crit Care Med. 2006; 34:589-597. [PubMed: 16505643]

207. Padbury JF, Agata Y, Baylen BG, et al. Pharmacokinetics of dopamine in critically ill newborn infants. J Pediatr. 1990; 117:472-476. [PubMed: 2391608] 
208. Bhatt-Mehta V, Nahata MC, McClead RE, et al. Dopamine pharmacokinetics in critically ill newborn infants. Eur J Clin Pharmacol. 1991; 40:593-597. [PubMed: 1884740]

209. Allen E, Pettigrew A, Frank D, et al. Alterations in dopamine clearance and catechol-Omethyltransferase activity by dopamine infusions in children. Crit Care Med. 1997; 25:181-189. [PubMed: 8989196]

210. Outwater KM, Treves ST, Lang P. Renal and hemodynamic effects of dopamine in infants following cardiac surgery. J Clin Anesth. 1990; 2:253-257. [PubMed: 2117937]

211. Lobe TE, Paone R, Dent SR. Benefits of high-dose dopamine in experimental neonatal septic shock. J Surg Res. 1987; 42:665-674. [PubMed: 3295394]

212. Seri I, Tulassay T, Kiszel J, et al. Cardiovascular response to dopamine in hypotensive preterm neonates with severe hyaline membrane disease. Eur J Pediatr. 1984; 142:3-9. [PubMed: 6714257]

213. Padbury JF, Agata Y, Baylen BG, et al. Dopamine pharmacokinetics in critically ill newborn infants. J Pediatr. 1987; 110:293-298. [PubMed: 3806305]

214. Hentschel R, Hensel D, Brune T, et al. Impact on blood pressure and intestinal perfusion of dobutamine or dopamine in hypotensive preterm infants. Biol Neonate. 1995; 68:318-324. [PubMed: 8835086]

215. Klarr JM, Faix RG, Pryce CJ. Randomized, blind trial of dopamine versus dobutamine for treatment of hypotension in preterm infants with respiratory distress syndrome. J Pediatr. 1994; 125:117-122. [PubMed: 8021760]

216. Liet JM, Boscher C, Gras-Leguen C, et al. Dopamine effects on pulmonary artery pressure in hypotensive preterm infants with patent ductus arteriosus. J Pediatr. 2002; 149:373-375. [PubMed: 11953739]

217. Meadows D, Edwards JD, Wilkins RG, et al. Reversal of intractable septic shock with norepinephrine therapy. Crit Care Med. 1988; 16:663-666. [PubMed: 3371042]

218. Desjars P, Pinaud M, Potel G, et al. A reappraisal of norepinephrine therapy in human septic shock. Crit Care Med. 1987; 15:134-137. [PubMed: 3802857]

219. Hall LG, Oyen LJ, Taner CB, et al. Fixed-dose vasopressin compared with titrated dopamine and norepinephrine as initial vasopressor therapy for septic shock. Pharmacotherapy. 2004; 24:1002_ 1112. [PubMed: 15338849]

220. Delmas A, Leone M, Rousseau S, Clinical review, et al. Vasopressin and terlipressin in septic shock patients. Critical Care. 2005; 9:212-222. [PubMed: 15774080]

221. Leibovitch L, Efrati O, Vardi A, et al. Intractable hypotension in septic shock: Successful treatment with vasopressin in an infant. Isr Med Assoc J. 2003; 5:596-598. [PubMed: 12929303]

222. Matok I, Vard A, Efrati O, et al. Terlipressin as rescue therapy for intractable hypotension due to septic shock in children. Shock. 2005; 23:305-310. [PubMed: 15803052]

223. Tsuneyoshi I, Yamada H, Kakihana Y, et al. Hemodynamic and metabolic effects of low-dose vasopressin infusions in vasodilatory septic shock. Crit Care Med. 2001; 29:487-493. [PubMed: 11373409]

224. Peters MJ, Booth RA, Petros AJ. Terlipressin bolus induces systemic vasoconstriction in septic shock. Pediatric Crit Care Med. 2004; 5:112-115.

225. Liedel JL, Meadow W, Nachman J, et al. Use of vasopressin in refractory hypotension in children with vasodilatory shock: Five cases and a review of the literature. Pediatr Crit Care Med. 2002; 3:15-18. [PubMed: 12793916]

226. Vasudevan A, Lodha R, Kabra SK. Vasopressin infusion in children with catecholamine-resistant septic shock. Acta Paediatr. 2005; 94:380-383. [PubMed: 16028663]

227. Rodriguez-Nunez A, Fernandez-Sanmartin M, Martinon-Torres F, et al. Terlipressin for catecholamine-resistant septic shock in children. Intensive Care Med. 2004; 30:477-480. [PubMed: 14767584]

228. Matok I, Leibovitch L, Vardi A, et al. Terlipressin as rescue therapy for intractable hypotension during neonatal septic shock. Pediatr Crit Care Med. 2004; 5:116-118. [PubMed: 14987339]

229. Rosenzweig EB, Starc TJ, Chen JM, et al. Intravenous arginine-vasopressin in children with vasodilatory shock after cardiac surgery. Circulation. 1999; 100(Suppl 19):11182-11186. 
230. Peters MJ, Booth RA, Petros AJ. Terlipressin bolus induces systemic vasoconstriction in septic shock. Pediatr Crit Care Med. 2004; 5:188-189. [PubMed: 15080105]

231. Yunge M, Petros A. Angiotensin for septic shock unresponsive to noradrenaline. Arch Dis Child. 2000; 82:388-389. [PubMed: 10799431]

232. Gregory JS, Binfiglio NF, dasta JF, et al. Experience with phenylephrine as a component of pharmacologic support of septic shock. Crit Care Med. 1991; 19:1395-1340. [PubMed: 1935160]

233. Grover R, Lopez A, Lorente J, et al. Multicenter, randomized, double blind, placebo-controlled, double bind study of nitric oxide inhibitor 546C88: Effect on survival in patients with septic shock. Crit Care Med. 1999; 27:A33.

234. Driscoll W, Thutin S, Carrion V, et al. Effect of methylene blue on refractory neonatal hypotension. J Pediatr. 1996; 129:904-908. [PubMed: 8969734]

235. Taylor K, Holtby H. Methylene blue revisited: Management of hypotension in a pediatric patient with bacterial endocarditis. J Thorac Cardiovasc Surg. 2005; 130:566. [PubMed: 16077431]

236. Copper DJ, Russell JA, Walley KR, et al. Vasopressin and septic shock trial (VASST): Innovative features and performance. Am J Respir Crit Care Med. 2003; 167:A838.

237. Choong, K.; Menon, K.; Litalien, C., et al. A study of the efficacy of vasopressin in pediatric vasodilatory shock. Available at: http://www.controlled-trials.com/isrctn/trial//0/11597444.html

238. LeClerc F, Walter-Nicolet E, Leteutre S, et al. Admission plasma vasopressin levels in children with meningococcal septic shock. Intensive Care Med. 2003; 29:1339-1344. [PubMed: 12856123]

239. Lin JC, Carcillo JA. Increased glucose/ glucose infusion rate ratio predicts anion gap acidosis in pediatric sepsis. Crit Care Med. 2004; 32(Suppl 20):A5.

240. Drop LJ, Laver MB, Roberton NR, et al. Low plasma ionized calcium and response to calcium therapy in critically ill man. Anesthesiology. 1975; 43:300-306. [PubMed: 240298]

241. Cardenas-Rivero N, Chernow B, Stoiko MA, et al. Hypocalcemia in critically ill children. J Pediatr. 1989; 114:946-951. [PubMed: 2786063]

242. Sumarmo. The role of steroids in dengue shock syndrome. Southeast Asian J Trop Med Public Health. 1987; 18:383-389. [PubMed: 3324364]

243. Min M, U T, Aye M, et al. Hydrocortisone in the management of dengue shock syndrome. Southeast Asian J Trop Med Public Health. 1975; 6:573-579. [PubMed: 131976]

244. Hatherill M, Tibby SM, Hilliard T, et al. Adrenal insufficiency in septic shock. Arch Dis Child. 1999; 80:51-55. [PubMed: 10325759]

245. Ryan CA. Fatal childhood pneumococcal Waterhouse-Friderichsen syndrome. Pediatr Infect Dis J. 1993; 12:250-251. [PubMed: 8451106]

246. Kohane, DS. Endocrine, mineral, and metabolic disease in pediatric intensive care. In: Rogers, MC., editor. Textbook of Pediatric Intensive Care. Baltimore: Williams and Wilkins; 1996.

247. Matot I, Sprung CL. Corticosteroids in septic shock: Resurrection of the last rites? Crit Care Med. 1998; 26:627-629. [PubMed: 9559592]

248. Briegel J, Forst H, Kellermann W, et al. Hemodynamic improvement in refractory septic shock with cortisol replacement therapy. Intensive Care Med. 1992; 18:318. [PubMed: 1527269]

249. Moran JL, Chapman MJ, O'Fathartaigh MS, et al. Hypocortisolaemia and adrenocortical responsiveness at onset of septic shock. Intensive Care Med. 1994; 20:489-495. [PubMed: 7995865]

250. Todd JK, Ressman M, Caston SA, et al. Corticosteroid therapy for patients with toxic shock syndrome. JAMA. 1984; 252:3399-3402. [PubMed: 6389917]

251. Sonnenschein H, Joos HA. Hydrocortisone treatment of endotoxin shock. Another paradox in pediatrics. Clin Pediatr. 1970; 9:251-252.

252. The American Hospital Formulary. 1998

253. Bettendorf M, Schmitt KG, Grulich Henn J, et al. Tri-iodothyronine treatment in children after cardiac surgery a double blind, randomized placebo controlled study. Lancet. 2000; 356:529 534. [PubMed: 10950228] 
254. Joosten KF, deKleign ED, Westerndorp M, et al. Endocrine and metabolic responses in children with meningococcal sepsis; striking differences between survivors and nonsurvivors. J Clin Endocrinol Metab. 2000; 85:3746-3753. [PubMed: 11061534]

255. Riordan FA, Thomson AP, Ratcliffe JM, et al. Admission cortisol and adrenocorticotropin hormone levels in children with meningococcal disease: Evidence of adrenal insufficiency? Crit Care Med. 1999; 27:2257-2261. [PubMed: 10548217]

256. Soni A, Pepper GM, Wyrwinski PM, et al. Adrenal insufficiency occurring during septic shock, incidence, outcome, and relationship to peripheral cytokine levels. Am J Med. 1995; 98:266-271. [PubMed: 7872343]

257. Migeon CJ, Kenny FM, Hung W, et al. Study of adrenal function in children with meningitis. Pediatrics. 1967; 40:163-181. [PubMed: 5006579]

258. Sonnenschein H, Joos HA. Use and dosage of hydrocortisone in endotoxic shock. Pediatrics. 1970; 45:720. [PubMed: 5438183]

259. Hodes HL. Care of the critically ill child: Endotoxic shock. Pediatrics. 1969; 44:248-260. [PubMed: 5806255]

260. Annane D, Sebille V, Charpentier C, et al. Effect of treatment with low doses of hydrocortisone and fludrocortisone on mortality in patients with septic shock. JAMA. 2002; 288:862-871. [PubMed: 12186604]

261. Lichtarowicz-Krynska EJ, Cole TJ, Camacho-Hubner C, et al. Circulating aldosterone levels are unexpectedly low in children with acute meningococcal disease. J Clin Endocrinol Metab. 2004; 89:1410-1414. [PubMed: 15001642]

262. Lodygensky GA, Rademaker K, Zimine S, et al. Structural and functional brain development after hydrocortisone treatment for neonatal chronic lung disease. Pediatrics. 2005; 116:1-7. [PubMed: 15995023]

263. Committee on Fetus and Newborn. Postnatal corticosteroids to treat or prevent chronic lung disease in preterm infants. Pediatrics. 2002; 109:330-338. [PubMed: 11826218]

264. Seri I. Hydrocortisone and vasopressor-resistant shock in preterm neonates. Pediatrics. 2006; 117:516-518. [PubMed: 16452371]

265. De Kleijn ED, Joosten KF, Van Rijn B, et al. Low serum cortisol in combination with high adrenocorticotrophic hormone concentrations are associated with poor outcome in children with severe meningococcal disease. Pediatr Infect Dis J. 2002; 21:330-336. [PubMed: 12075765]

266. Onenli-Mungan N, Yildizdas D, Yapicioglu H, et al. Growth hormone and insulin-like growth factor 1 levels and their relation to survival in children with bacterial sepsis and septic shock. $\mathbf{J}$ Paediatr Child Health. 2004; 40:221-226. [PubMed: 15009554]

267. den Brinker M, Joosten KF, Visser TJ, et al. Euthyroid sick syndrome in meningococcal sepsis: The impact of peripheral thyroid hormone metabolism and binding proteins. J Clin Endocrinol Metab. 2005; 90:5613-5620. [PubMed: 16076941]

268. Markovitz BP, Goodman DM, Watson RS, et al. A retrospective cohort study of prognostic factors associated with outcome in pediatric severe sepsis: What is the role of steroids? Pediatr Crit Care Med. 2005; 6:270-274. [PubMed: 15857523]

269. Burmester M, Pierce C, Petros A. Disseminated candidiasis after steroid treatment for early neonatal hypotension. Arch Dis Child Fetal Neonatal Ed. 2001; 85:F226. [PubMed: 11710324]

270. Roberts JD Jr, Rinnai JR, Main FC III, et al. Inhaled nitric oxide and persistent pulmonary hypertension of the newborn. The Inhaled Nitric Oxide Study Group. N Engl J Med. 1997; 336:605-610. [PubMed: 9032045]

271. Inhaled Nitric Oxide Study Group. Inhaled nitric oxide in full term and nearly full-term infants with hypoxic respiratory failure. N Engl J Med. 1997; 336:597-604. [PubMed: 9036320]

272. Wung JT, James LS, Kilchevsky E. Management of infants with severe respiratory failure and persistence of the fetal circulation, without hyperventilation. Pediatrics. 1985; 76:488-494. [PubMed: 4047792]

273. Drummond WH, Gregory GA, Heyman MA, et al. The independent effects of hyperventilation, tolazoline, and dopamine on infants with persistent pulmonary hypertension need to be taken into consideration when using these drugs. J Pediatr. 1981; 98:603-611. [PubMed: 6782220] 
274. Drummond WH. Use of cardiotonic therapy in the management of infants with PPHN. Clin Perinatol. 1984; 11:715-728. [PubMed: 6488674]

275. Gouyon JB, Francoise M. Vasodilators in persistent pulmonary hypertension of the newborn: A need for optimal appraisal of efficacy. Dev Pharmacol Ther. 1992; 19:62-68. [PubMed: 1340438]

276. Meadow WL, Meus PJ. Hemodynamic consequences of tolazoline in neonatal group B streptococcal bacteremia: An animal model. Pediatr Res. 1984; 18:960-965. [PubMed: 6387608]

277. Sandor GG, Macnab AJ, Akesode FA, et al. Clinical and echocardiographic evidence suggesting afterload reduction as a mechanism of action of tolazoline in neonatal hypoxemia. Pediatr Cardiol. 1984; 5:93-99. [PubMed: 6473128]

278. Benitz WE, Malachowski N, Cohen RS, et al. Use of sodium nitroprusside in neonates: Efficacy and safety. J Pediatr. 1985; 106:102-110. [PubMed: 3917495]

279. McNamara PJ, Laique F, Muang-In S, et al. Milrinone improves oxygenation in neonates with severe persistent pulmonary hypertension of the newborn. J Crit Care. 2006; 21:217-222. [PubMed: 16769471]

280. Bassler D, Choong K, McNamara P, et al. Neonatal persistent pulmonary hypertension treated with milrinone: Four case reports. Biol Neonate. 2006; 89:1-5. [PubMed: 16155380]

281. Rahis N, Morin FCIII, Swartz DD, et al. Effects of prostacyclin and milrinone on pulmonary hemodynamics in newborn lambs with persistent pulmonary hypertension induced by ductal ligation. Pediatr Res. 2006; 60:624-629. [PubMed: 16988189]

282. Bartlett RH, Roloff DW, Custer JR, et al. Extracorporeal life support: The University of Michigan experience. JAMA. 2000; 283:904-908. [PubMed: 10685715]

283. Meyer DM, Jessen ME. Results of extracorporeal membrane oxygenation in neonates with sepsis. The Extracorporeal Life Support Organization experience. J Thorac Cardiovasc Surg. 1995; 109:419-425. [PubMed: 7877302]

284. Bernbaum J, Schwartz IP, Gerdes M, et al. Survivors of extracorporeal oxygenation at 1 year of age: The relationship of primary diagnosis with health and neurodevelopmental sequalae. Pediatrics. 1995; 96(5 Pt 1):907-913. [PubMed: 7478834]

285. The collaborative UK ECMO (Extracorporeal Membrane Oxygenation) trial: Follow-up to 1 year of age. Pediatrics. 1998; 101:E1.

286. Cincheiro, Guisan A.; Sousa, Rouco C.; Suarez, Traba B.; Inhaled, iloprost, et al. A therapeutic alternative for persistent pulmonary hypertension of the newborn. Ann Pediatr. 2005; 63:175176.

287. Ehlen M, Wiebe B. Iloprost in persistent pulmonary hypertension of the newborn. Cardiol Young. 2003; 13:361-363. [PubMed: 14694957]

288. Patole S, Lee J, Buettner P, et al. Improved oxygenation following adenosine infusions in persistent pulmonary hypertension of the newborn. Biol Neonate. 1998; 74:345-350. [PubMed: 9742263]

289. Konduri GG, Garcia DC, Kazzi NJ, et al. Adenosine infusion improves oxygenation in term infants with respiratory failure. Pediatrics. 1996; 97:295-300. [PubMed: 8604260]

290. Motti A, Tissot C, Romensberger PC, et al. Intravenous adenosine for refractory pulmonary hypertension in a low-birthweight premature newborn: A potential new drug for rescue therapy. Pediatr Crit Care Med. 2006; 7:380-382. [PubMed: 16738499]

291. Ng C, Franklin O, Vaidya M, et al. Adenosine infusion for the management of persistent pulmonary hypertension of the newborn. Pediatr Crit Care Med. 2004; 5:10-13. [PubMed: 14697102]

292. Meyer DM, Jessen ME. Results of extracorporeal membrane oxygenation in children with sepsis. The Extracorporeal Life Support Organization. Ann Thorac Surg. 1997; 63:756-761. [PubMed: 9066397]

293. Goldman AP, Kerr SJ, Butt W. Extracorporeal support for intractable cardiorespiratory failure due to meningococcal disease. Lancet. 1997; 349:466-469. [PubMed: 9040577]

294. Beca J, Butt W. Extracorporeal membrane oxygenation for refractory septic shock in children. Pediatrics. 1994; 93:726-729. [PubMed: 8165069] 
295. Dalton HJ, Siewers RD, Fuhrman BP, et al. Extracorporeal membrane oxygenation for cardiac rescue in children with severe myocardial dysfunction. Crit Care Med. 1993; 21:1020-1028. [PubMed: 8319459]

296. Hallin GW, Simpsom SQ, Crowell RE. Cardiopulmonary manifestations of Hantavirus pulmonary syndrome. Crit Care Med. 1996; 24:252-258. [PubMed: 8605797]

297. Crowley MR, Katz RW, Kessler R, et al. Successful treatment of adults with Hantavirus pulmonary syndrome with ECMO. Crit Care Med. 1998; 26:409-414. [PubMed: 9468181]

298. Jeffers A, Gladwin MT, Kim-Shapiro DB. Computation of plasma hemoglobin nitric oxide scavenging in hemolytic anemias. Free Radic Biol Med. 2006; 41:1557-1565. [PubMed: 17045924]

299. Jackson EK, Koehler M, Mi Z, et al. Possible role fo adenosine deaminase in vaso-occlusive disease. J Hypertens. 1996; 14:19-29. [PubMed: 12013490]

300. Fortenberry JD, Paden ML. Extracorporeal therapies in the treatment of sepsis: Experience and promise. Semin Pediatr Infect Dis. 2006; 17:72-79. [PubMed: 16822469]

301. Smith OP, White B, Vaughan D, et al. Use of protein C concentrate, heparin, and hemodiafiltration in meningococcus induced purpura fulminans. Lancet. 1997; 350:1590-1593. [PubMed: 9393338]

302. Ratanarat R, Brendolan A, Ricci Z, et al. Pulse high volume hemofiltration in critically ill patients: A new approach for patients with septic shock. Semin Dial. 2006; 19:69-74. [PubMed: 16423184]

303. Piccini P, Dan M, Barbacini S, et al. Early isovolemic haemofiltration in oliguric patients with septic shock. Intensive Care Med. 2006; 32:80-86. [PubMed: 16328222]

304. Bock KR. Renal replacement therapy in pediatric critical care medicine. Curr Opin Pediatr. 2005; 17:368-371. [PubMed: 15891428]

305. Maheshwari P, Chhabra R, Clement M, et al. Hemodynamic changes during hemofiltration in meningococcal septicaemia. Euro-pediatrics. 2006:61.

306. Krovetz JL, Goldbloom S. Hemodynamics in normal children. Johns Hopkins Med J. 1971; 130:187-195. [PubMed: 5060758]

307. Report of the second task force on blood pressure control in children-1987. Task Force on Blood Pressure Control in Children. National Heart, Lung, and Blood Institute, Bethesda, MD. Pediatrics. 1987; 79:1-25. [PubMed: 3797155] 


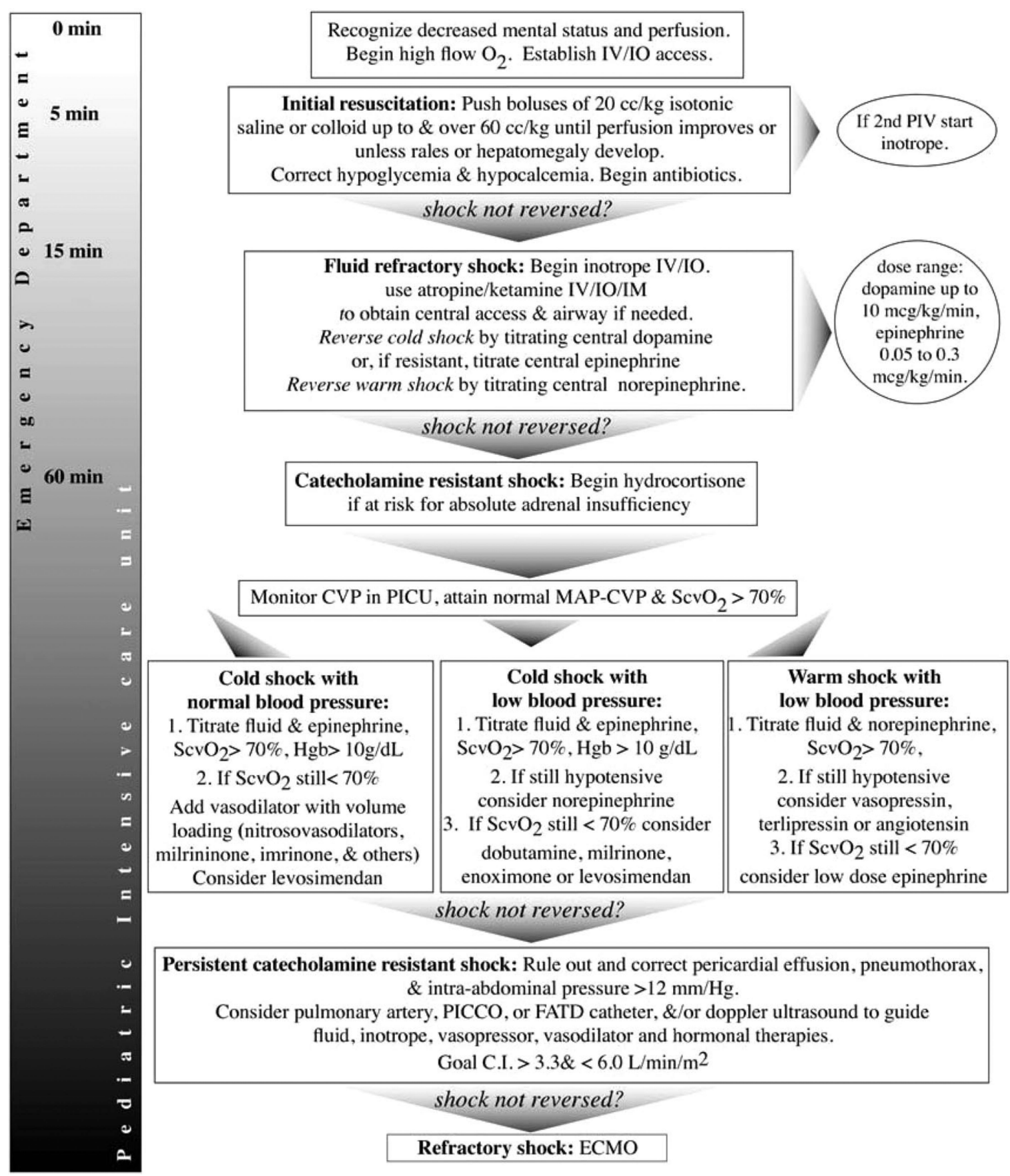

Figure 1.

Algorithm for time sensitive, goal-directed stepwise management of hemodynamic support in infants and children. Proceed to next step if shock persists. 1) First hour goals-Restore and maintain heart rate thresholds, capillary refill $\_$sec, and normal blood pressure in the first hour/emergency department. Support oxygenation and ventilation as appropriate. 2) Subsequent intensive care unit goals-If shock is not reversed, intervene to restore and maintain normal perfusion pressure (mean arterial pressure $[M A P]$-central venous pressure $[C V P]$ ) for age, central venous $\mathrm{O}_{2}$ saturation $>70 \%$, and $\mathrm{CI}>3.3,<6.0 \mathrm{~L} / \mathrm{min} / \mathrm{m}^{2}$ in pediatric 
intensive care unit (PICU). Hgb, hemoglobin; PICCO, pulse contour cardiac output; FATD, femoral arterial thermodilution; $E C M O$, extracorporeal membrane oxygenation; $C I$, cardiac index; $C R R T$, continuous renal replacement therapy; $I V$, intravenous; $I O$, interosseous; $I M$, intramuscular. 


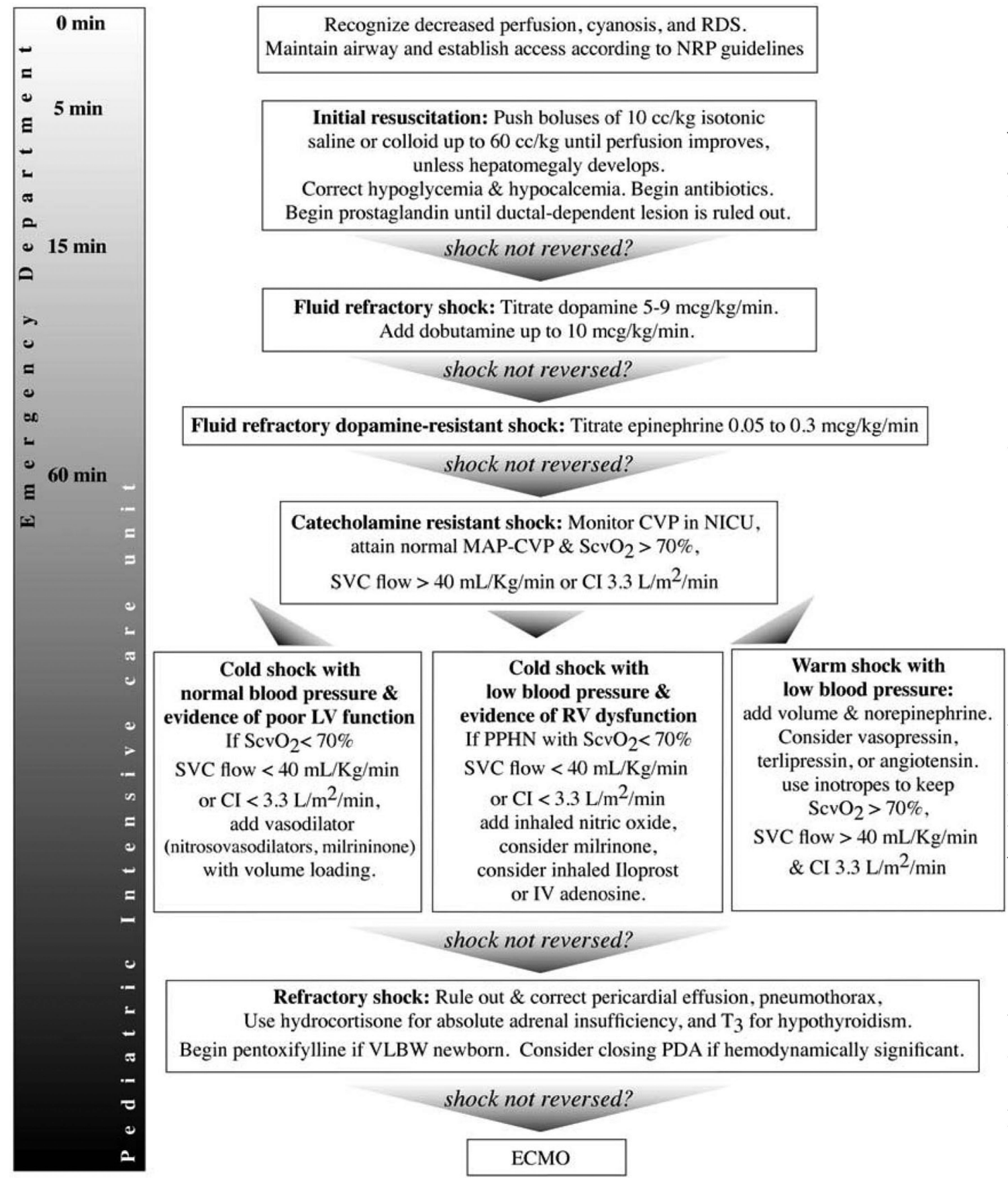

Figure 2.

Algorithm for time sensitive, goal-directed stepwise management of hemodynamic support in newborns. Proceed to next step if shock persists. 1) First hour goals-Restore and maintain heart rate thresholds, capillary refill $\mathcal{s} \mathrm{sec}$, and normal blood pressure in the (first hour), and 2) Subsequent intensive care unit goals-Restore normal perfusion pressure (mean arterial pressure $[M A P]$-central venous pressure $[C V P]$ ), preductal and postductal $\mathrm{O}_{2}$ saturation difference $<5 \%$, and either central venous $\mathrm{O}_{2}$ saturation $\left(\mathrm{ScvO}_{2}\right)>70 \%$, superior vena cava $(S V C)$ flow $>40 \mathrm{ml} / \mathrm{kg} / \mathrm{min}$ or cardiac index $(C I)>3.3 \mathrm{~L} / \mathrm{min} / \mathrm{m}^{2}$ in neonatal 
intensive care unit (NICU). RDS, respiratory distress syndrome; $N R P$, Neonatal Resuscitation Program; PDA, patent ductus arteriosus; ECMO, extracorporeal membrane oxygenation. 


\section{Table 1}

American College of Critical Care Medicine guidelines for evidence-based medicine rating system for strength of recommendation and quality of evidence supporting the references

\begin{tabular}{ll}
\hline Rating system for references \\
a & Randomized, prospective controlled trial \\
b & Nonrandomized, concurrent or historical cohort investigations \\
c & $\begin{array}{l}\text { Peer-reviewed, state of the art articles, review articles, editorials, or substantial } \\
\text { case series }\end{array}$ \\
d & $\begin{array}{l}\text { Nonpeer reviewed published opinions, such as textbook statements or official } \\
\text { organizational publications }\end{array}$ \\
Rating system for recommendations & $\begin{array}{l}\text { Convincingly justifiable on scientific evidence alone } \\
\text { Level 1 }\end{array}$ \\
Level 2 & $\begin{array}{c}\text { Reasonably justifiable by scientific evidence and strongly supported by expert critical } \\
\text { care opinion }\end{array}$ \\
Level 3 & $\begin{array}{c}\text { Adequate scientific evidence is lacking but widely supported by available data and } \\
\text { expert opinion }\end{array}$ \\
\hline
\end{tabular}


Table 2

American College of Critical Care Medicine hemodynamic definitions of shock

\begin{tabular}{ll}
\hline Cold or warm shock & $\begin{array}{c}\text { Decreased perfusion manifested by altered decreased mental status, } \\
\text { capillary refill }>2 \text { secs (cold shock) or flash capillary refill } \\
\text { (warm shock), diminished (cold shock) or bounding (warm } \\
\text { shock) peripheral pulses, mottled cool extremities (cold shock), } \\
\text { or decreased urine output }<1 \mathrm{~mL} / \mathrm{kg} / \mathrm{h}\end{array}$ \\
$\begin{array}{c}\text { Fluid-refractory/ } \\
\text { dopamine-resistant } \\
\text { shock }\end{array}$ & $\begin{array}{c}\text { Shock persists despite } 260 \mathrm{~mL} / \mathrm{kg} \text { fluid resuscitation (when } \\
\text { appropriate) and dopamine infusion to } 10 \mu \mathrm{g} / \mathrm{kg} / \mathrm{min}\end{array}$ \\
$\begin{array}{c}\text { Catecholamine-resistant } \\
\text { shock }\end{array}$ & $\begin{array}{c}\text { Shock persists despite use of the direct-acting catecholamines; } \\
\text { epinephrine or norepinephrine }\end{array}$ \\
Refractory shock & $\begin{array}{c}\text { Shock persists despite goal-directed use of inotropic agents, } \\
\text { vasopressors, vasodilators, and maintenance of metabolic } \\
\text { (glucose and calcium) and hormonal (thyroid, hydrocortisone, } \\
\text { insulin) homeostasis }\end{array}$ \\
\hline
\end{tabular}

Crit Care Med. Author manuscript; available in PMC 2015 May 28. 
Table 3

Threshold heart rates and perfusion pressure mean arterial pressure-central venous pressure or mean arterial pressure-intra-abdominal pressure for age

\begin{tabular}{lrc}
\hline Threshold Rates & $\begin{array}{r}\text { Rate (bpm) } \\
\text { Heart }\end{array}$ & $\begin{array}{c}\text { Mean Arterial } \\
\text { Pressure-Central } \\
\text { Venous Pressure } \\
(\mathbf{m m ~ H g})\end{array}$ \\
\hline Term newborn & $120-180$ & 55 \\
Up to 1 yr & $120-180$ & 60 \\
Up to 2 yrs & $120-160$ & 65 \\
Up to 7 yrs & $100-140$ & 65 \\
Up to 15 yrs & $90-140$ & 65 \\
\hline
\end{tabular}

bpm, beats per minute.

Modified from The Harriet Lane Handbook. Thirteenth Edition and National Heart, Lung, and Blood Institute, Bethesda. MD: Report of the second task force on blood pressure control in children - 1987 (306, 307). 